\title{
Material Characterisation and Computational Thermal Modelling of Electron Beam Powder Bed Fusion Additive Manufacturing of Ti2448 Titanium Alloy
}

\author{
Qiushuang Wang ${ }^{1,2,+}$, Wenyou Zhang ${ }^{3,4,5,+}$, Shujun Li ${ }^{1, *}$, Mingming Tong $3,4,5, * \mathbb{C}$, Wentao Hou ${ }^{1}$, \\ Hao Wang ${ }^{1}{ }^{(}$, Yulin Hao ${ }^{1, *}$, Noel M. Harrison ${ }^{3,4,5}$ and Rui Yang ${ }^{1}$ \\ 1 Institute of Metal Research, Chinese Academy of Sciences, Shenyang 110016, China; \\ qswang18b@imr.ac.cn (Q.W.); wthou@imr.ac.cn (W.H.); haowang@imr.ac.cn (H.W.); ryang@imr.ac.cn (R.Y.) \\ 2 School of Materials Science and Engineering, University of Science and Technology of China, \\ Shenyang 110016, China \\ 3 I-Form, SFI Research Centre for Advanced Manufacturing, Ireland; W.ZHANG2@nuigalway.ie (W.Z.); \\ noel.harrison@nuigalway.ie (N.M.H.) \\ 4 Mechanical Engineering, School of Engineering, College of Science and Engineering, NUI Galway, \\ H91 TK33 Galway, Ireland \\ 5 Ryan Institute for Environmental, Marine and Energy Research, NUI Galway, H91 TK33 Galway, Ireland \\ * Correspondence: shjli@imr.ac.cn (S.L.); mingming.tong@nuigalway.ie (M.T.); ylhao@imr.ac.cn (Y.H.) \\ + These authors contributed equally to this work.
}

check for updates

Citation: Wang, Q.; Zhang, W.; Li, S.; Tong, M.; Hou, W.; Wang, H.; Hao, Y.; Harrison, N.M.; Yang, R. Material Characterisation and Computational Thermal Modelling of Electron Beam Powder Bed Fusion Additive Manufacturing of Ti2448 Titanium Alloy. Materials 2021, 14, 7359. https://doi.org/10.3390/ma14237359

Academic Editor: Amir Mostafaei

Received: 11 October 2021

Accepted: 26 November 2021

Published: 30 November 2021

Publisher's Note: MDPI stays neutral with regard to jurisdictional claims in published maps and institutional affiliations.

Copyright: (c) 2021 by the authors. Licensee MDPI, Basel, Switzerland. This article is an open access article distributed under the terms and conditions of the Creative Commons Attribution (CC BY) license (https:// creativecommons.org/licenses/by/ $4.0 /)$.
Abstract: Ti-24Nb-4Zr-8Sn (Ti2448) is a metastable $\beta$-type titanium alloy developed for biomedical applications. In this work, cylindrical samples of Ti2448 alloy have been successfully manufactured by using the electron beam powder bed fusion (PBF-EB) technique. The thermal history and microstructure of manufactured samples are characterised using computational and experimental methods. To analyse the influence of thermal history on the microstructure of materials, the thermal process of PBF-EB has been computationally predicted using the layer-by-layer modelling method. The microstructure of the Ti2448 alloy mainly includes $\beta$ phase and a small amount of $\alpha$ " phase. By comparing the experimental results of material microstructure with the computational modelling results of material thermal history, it can be seen that aging time and aging temperature lead to the variation of $\alpha^{\prime \prime}$ phase content in manufactured samples. The computational modelling proves to be an effective tool that can help experimentalists to understand the influence of macroscopic processes on material microstructural evolution and hence potentially optimise the process parameters of PBF-EB to eliminate or otherwise modify such microstructural gradients.

Keywords: electron beam powder bed fusion; thermal process modelling; Ti2448 alloy; phase transformation; computational modelling

\section{Introduction}

Powder Bed Fusion (PBF) is a category of Additive Manufacturing (AM) technology that constructs 3D parts in a layer-by-layer manner. The heat source can either be electron beam (PBF-EB, with a common trademark being electron beam melting (EBM)) or laser beam (PBF-LB, with a common trademark being selective laser melting (SLM)) [1]. PBF-EB employs a high energy electron beam as the heat source to heat and melt the powder material, which in turn solidifies rapidly as the electron beam moves on to form the final solid parts. The complex thermal processes during PBF-EB have significant influence on the overall properties and in-service performance of manufactured parts [2]. For example, PBF-EB manufactured components can have a unique microstructure which consists of coarse columnar grains aligned in the $<001>$ orientation and equiaxed grains near the base plate [3]. Gradient microstructure is more likely to be formed in the PBF-EB process due to the extreme solidification conditions, such as high cooling rate, high thermal gradient 
and intense partitioning behaviour of alloying elements [4]. It is reported that the size of precipitates changes gradually in Inconel 718 alloy through PBF-EB process, which can be used to optimise the mechanical behaviour of the alloy [5]. The PBF-EB 316L stainless steel also shows a hierarchical microstructure. By optimising the process parameters, PBF-EB 316L stainless steel exhibited better mechanical properties and density than the same material manufactured by using powder metallurgy process (hot isostatic pressing) [6].

Mechanical properties of manufactured metallic parts using PBF-EB are closely related to the material microstructures. In order to be able to manufacture PBF-EB products that have desirable mechanical properties, it is necessary to understand the processmicrostructure relationship. To date, two different types of computational modelling techniques have been widely applied for computationally predicting the thermal processes of PBF-EB: the moving heat source method $[7,8]$ and the layer-by-layer method $[9,10]$. The moving heat source method directly models a high energy electron beam spot scanning the powder bed layer along the designed scanning paths (e.g., as presented in [11]). The layer-by-layer approach applies a uniformly distributed heat source instantaneously to a whole layer of the part, which is followed by cooling (as well as solidification) of the whole layer of the part and loose powder material (if included in the model). The moving heat source method is computationally intensive and therefore is generally employed for the computation of a small volume of material, or a single layer build [11]. The layer-by-layer method is relatively computationally economical and therefore is suitable for the thermomechanical modelling at the macroscale. Williams et al. [12] predicted the distortion of a cuboid part during PBF-LB by using the layer-by-layer method and the simulation result was within $10 \%$ of experimentally measured part distortion. Zhang et al. [13] employed a layer-scaling technique in the computational prediction of temperature and residual stress by using the layer-by-layer method for a PBF-LB process for Ti-6Al-4V alloy. Prabhakar et al. [9] investigated the mechanical behaviour of Inconel 718 during PBF-EB process by using the layer-by-layer method, and the modelling results were validated by using related experimental characterisation.

Ti-24Nb-4Zr-8Sn (Ti2448) alloy is a nontoxic $\beta$-type titanium alloy. It has relatively good compatibility with the natural bones due to its low elastic modulus in conjunction with a variety of outstanding material properties such as high fatigue strength, considerable ductility and good corrosion resistance $[14,15]$ etc. AM technology has been used to successfully manufacture Ti2448 medical products, such as hip stems, acetabulum cups and interbody fusion cages [16]. Hernandez et al. indicated that columnar $\beta$ grains and $\alpha^{\prime \prime}$-martensite plates were observed in the PBF-EB Ti2448 solid part [17]. Yang et al. [18] showed that columnar $\beta$ grains were surrounded by equiaxed $\beta$ grains near the boundary of melt pool in the PBF-LB Ti2448 alloy. The hard-wraps-soft effect caused by this kind of microstructure can improve the mechanical properties of titanium alloy [18]. Liu et al. found that the microstructure of scaffolds manufactured by PBF-EB and PBF-LB were composed of different phases due to the difference in powder bed temperature, and the single $\beta$ phase of PBF-LB Ti2448 alloy resulted in higher compressive strength and lower Young's modulus [19]. It can be seen that the microstructure characteristics of PBFLB and PBF-EB Ti2448 alloy are different and can influence the mechanical behaviours of manufactured parts. In order to obtain components with excellent comprehensive properties, it is necessary to fully understand the influence of process parameters on the microstructure formation by using computational modelling and experiments.

In this study, to analyze the temperature evolution of Ti2448 and its influence on microstructure during PBF-EB, the layer-by-layer approach was employed to computationally predict the thermal process of the PBF-EB AM of Ti2448 alloy at the scale of the overall additively manufactured component. The microstructure of manufactured PBF-EB Ti2448 parts was characterised using experimental methods and compared with the computational modelling results. It is the first time that experimental research on PBF-LB of Ti2448 alloy in conjunction with computational thermal modelling has been investigated. The 
computational modelling results are used in this paper to facilitate the discussion and interpretation of the experimental and microscopy results of manufactured samples.

\section{Materials and Methods}

\subsection{Computational Modelling Methods}

In former papers from the authors [13,22], a multi-physics computational model for PBF-LB was presented. It coupled a thermal sub-model with a sub-model of solid mechanics, to computationally predict the thermomechanical responses of Ti6Al4V during AM for the purpose of particularly predicting the residual stress. Following mesh convergence and layer scaling factor checks, the model was used to investigate how process parameters of PBF (e.g., scanning strategy) can affect the thermomechanical processes during PBFLB. Separately, their thermomechanical model was validated using synchrotron radiation on PBF-LB manufactured Ti6AL4V samples to experimentally characterise the residual stress [22]. For the purpose of model validation, multiple Ti6Al4V samples were practically manufactured by using PBF-LB with six different scanning strategies. The residual stress of samples was experimentally measured by using X-ray diffraction testing at a synchrotron radiation facility in Europe. For the same six different scanning strategies, the thermomechanical model was used to computationally predict the residual stress of related Ti6Al4V samples. A reasonable agreement was found between experimental results and computational modelling results of the residual stress of the samples. It proved that the thermomechanical model was reliable and effective, in terms of such as thermal modelling and mechanical modelling. Related details of the model validation process can be found in Zhang [22].

The following changes were made to the above thermomechanical model for PBF-LB of Ti6Al4V in this study for the PBF-EB of Ti2448 alloy.

- $\quad$ The solid mechanics sub-model was deactivated (only the thermal model was active).

- Material properties of Ti2448 were added as defined in Table 1.

- $\quad$ PBF-EB process parameters replaced PBF-LB process parameters (particularly considering the pre-heating step for each layer of powder bed during PBF-EB).

2.1.1. Setup of the Thermal Modelling Process and Simulation Domain The practical PBF-EB process consists of the following four steps [8,23]:

(a) A thin layer of powders (e.g., layer height of $40 \mu \mathrm{m}$ ) is deposited over a build platform and then is preheated by an electron beam operated in powder pre-heat mode.

(b) A finely focused electron beam (e.g., spot diameter of $200 \mu \mathrm{m}$ ) in melt mode rapidly melts the powders in a localised manner. It rapidly moves around the powder layer, tracing out the required $2 \mathrm{D}$ cross section of the $3 \mathrm{D}$ metallic parts.

(c) After the fabrication of one layer, the build platform moves down by one layer thickness and is ready for a new layer of loose powder to be spread.

The above three steps are repeated until the 3D component is completed.

For the convenience of the computational modelling in this study, the PBF-EB AM process is simplified to include the following four steps in the computation:

i. Preheating step in which the heat source preheats the powders to below melt temperature for a period of time defined as the preheating step time, $t_{\mathrm{p}}$, which represents the time spent on scanning the part by using the electron beam during the preheating step.

ii. Preheating 'cooling' step represents the time when the electron beam leaves the part and moves to preheat other areas of the powder bed for a period of preheating 'cooling' step time, $t_{\mathrm{c}}$. The total preheating time, $t_{1}$, is the sum of $t_{\mathrm{c}}$ and $t_{\mathrm{p}}$.

iii. Active layer melting step is when the finely focused electron beam operates in melt mode, heating the powders to above liquidus temperature. By active layer, it refers to the newly added layer of powders. The active layer melting step time, $t_{\mathrm{m}}$, can be calculated as the electron beam spot diameter divided by the electron beam moving 
speed for melting the powders, and assumes a constant beam scanning speed within a layer.

iv. Melting cooling step is the step in which the electron beam is deactivated and the roller/coater spreads a new thin layer of powders on the powder bed.

The above four computational steps (i-iv) are repeated for each layer during the PBFEB thermal modelling process. After finishing the final layer, there is an additional final cooling step in which the part is allowed to cool to room temperature for $8 \mathrm{~h} 43 \mathrm{~min}$ with no more deposition of powders and no more heat input in the computational modelling.

During the practical PBF-EB process, a cylinder sample in the dimension of $20 \mathrm{~mm}$ diameter $\times 20 \mathrm{~mm}$ height was built on a $10 \mathrm{~mm}$ thick base plate. As shown in Figure 1, a 2D axisymmetric simulation domain was employed in the thermal process modelling. In the practical PBF-EB process, the base plate temperature was approximately constant (around $773 \mathrm{~K}$ ). In the computational model, the priority is the thermal history of the part, rather than the whole base plate. For the convenience of computational modelling, isothermal boundary condition (constant temperature of $773 \mathrm{~K}$ ) was applied at the interface between the part and the base plate. Therefore, the size of the base plate that was employed in the setup of computational modelling $(20 \mathrm{~mm} \times 10 \mathrm{~mm}$ as shown in Figure 1) does not have to reflect the size of actual base plate. A python-based script for finite element software ABAQUS FEA package (Dassault Systemes, Johnston, SC, USA, 2017) was programmed to convert the macroscale geometry into 286 layer-by-layer slices [13,24]. During the computation for each layer, an element-birth technique $[13,21,25]$ was employed. The converged (less than $0.19 \%$ nodal temperature difference) mesh size of $23 \mu \mathrm{m} \times 23 \mu \mathrm{m}$ was employed for the part. The four-node linear axisymmetric heat transfer quadrilateral mesh type of DCAX4 was employed.

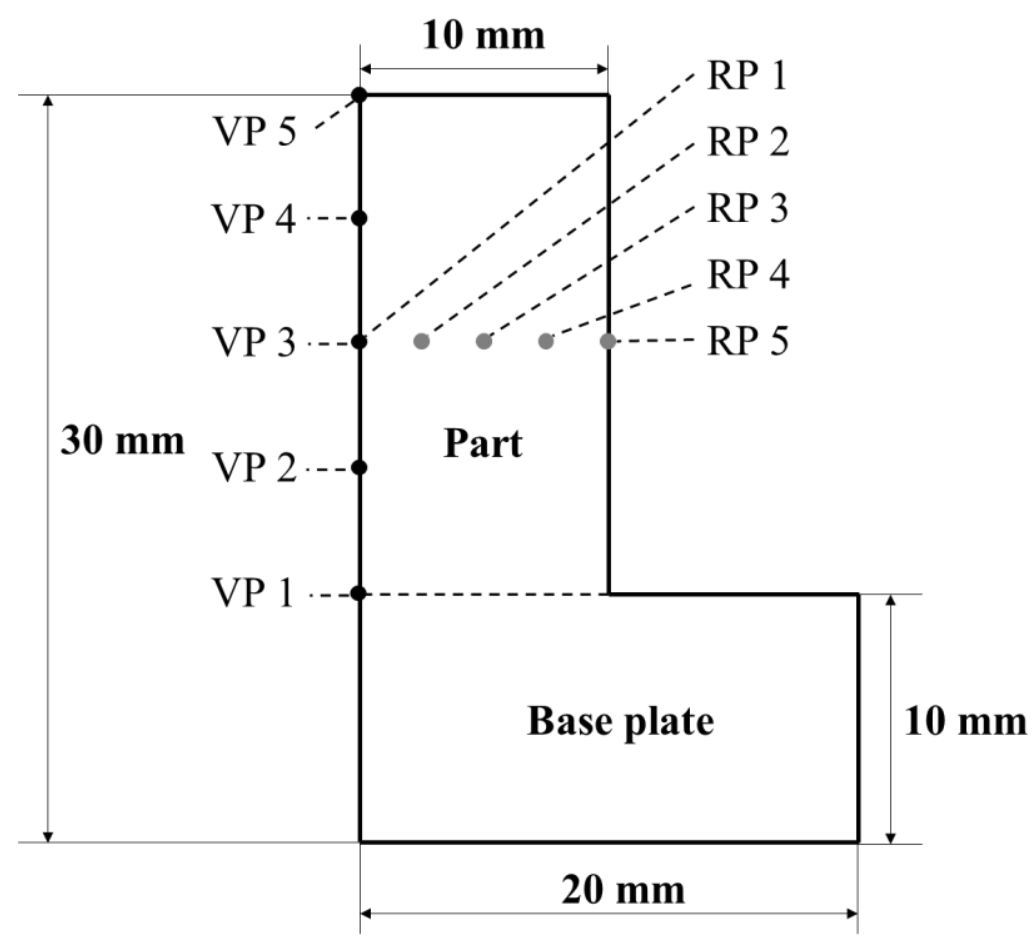

Figure 1. Geometry of the simulation domain and position of sampling points ("VP" for sampling points along the centreline i.e., height of cylindrical sample, "RP" for sampling points along the radius of cylindrical sample at its mid-height).

The results of thermal modelling were analysed at 10 different sampling points, including five evenly distributed sampling points (the VP points) along the height of the $2 \mathrm{D}$ part at its centre and five sampling points (the RP points) along the radius of the $2 \mathrm{D}$ 
part at its mid height as shown in Figure 1. The 5 VP points correspond to layer 1, layer 72, layer 143, layer 214 and layer 285 in the modelling, respectively.

\subsubsection{Thermal Modelling for the PBF-EB Process by Using Finite Element Method}

The thermal modelling in this study was implemented by computationally solving the following governing equations using the finite element method with ABAQUS. The energy equation that was employed in the thermal modelling for the PBF-EB process is $[10,26]$ :

$$
\rho_{\mathrm{s}} C_{\mathrm{p}} \frac{d T}{d t}+\rho_{\mathrm{s}} \frac{d(f L)}{d t}+\nabla \cdot q=0
$$

where $\rho_{\mathrm{s}}$ is for density, $C_{\mathrm{p}}$ for specific heat capacity, $T$ for temperature, $t$ for time, $L$ for latent heat of fusion, and $q$ for heat flux. The liquid fraction $f$ is assumed to be a linear function of temperature [27] as:

$$
f=\left\{\begin{array}{c}
0 T<T_{\mathrm{S}} \\
\frac{T-T_{\mathrm{S}}}{T_{\mathrm{L}}-T_{\mathrm{S}}} T_{\mathrm{S}} \leq T \leq T_{\mathrm{L}} \\
1 T>T_{\mathrm{L}}
\end{array}\right.
$$

where $T_{\mathrm{S}}$ and $T_{\mathrm{L}}$ are the solidus and liquidus temperature, respectively.

In the layer-by-layer modelling, all finite elements of a layer were subjected to simultaneous material deposition and energy input processes [13]. The uniformly distributed volumetric heat sources for both preheating step and active layer melting step were applied for each whole active layer.

In the preheating step, the volumetric power density at the active layer of the 2D part in the layer-by-layer process is calculated as:

$$
Q_{\mathrm{v}}=\frac{A P_{\mathrm{p}}}{v_{\mathrm{p}} t_{\mathrm{p}} d_{\mathrm{m}} H}
$$

where $A$ is the heat source absorption coefficient, $P_{\mathrm{p}}$ is the electron beam power for preheating, $v_{\mathrm{p}}$ is the electron beam scanning speed during the preheating process, $t_{\mathrm{p}}$ is the preheating step time, $d_{\mathrm{m}}$ is the melt pool depth and $H$ is the hatch spacing. The electron beam power for preheating $P_{\mathrm{p}}$ is calculated as [23]:

$$
P_{\mathrm{p}}=U I_{\mathrm{p}}
$$

where $U$ and $I_{\mathrm{p}}$ are the acceleration voltage and electron beam current for preheating, respectively. The preheating step time $t_{\mathrm{p}}$ can be calculated as:

$$
t_{\mathrm{p}}=\frac{A_{\mathrm{p}}}{A_{\mathrm{b}}} t_{1}
$$

where $A_{\mathrm{p}}$ is the cross-sectional area of the part in question, $A_{\mathrm{b}}$ is the surface area of the entire powder bed and $t_{1}$ is the overall preheating time $(28 \mathrm{~s})$ for each layer during the manufacturing process. Equation (1) was computationally solved for $t_{\mathrm{p}}$ seconds for the preheating process.

In the preheating 'cooling' step of the thermal modelling, the preheating cooling step time $t_{\mathrm{c}}$ can be calculated as:

$$
t_{\mathrm{c}}=t_{1}-t_{\mathrm{p}}
$$

Equation (1) was computationally solved for $t_{\mathrm{c}}$ seconds for the preheating 'cooling' process. 
In the active layer melting step of the thermal modelling, the volume power density that was applied at the top layer of the computational domain is calculated as [13]:

$$
Q_{\mathrm{v}}=\frac{A P_{\mathrm{m}}}{d_{\mathrm{s}} d_{\mathrm{m}} H}
$$

where $P_{\mathrm{m}}$ is the electron beam power for melting and $d_{\mathrm{s}}$ is the electron beam diameter for melting. The electron beam power for melting $P_{\mathrm{m}}$ is calculated by:

$$
P_{\mathrm{m}}=U I_{\mathrm{m}}
$$

where $I_{\mathrm{m}}$ is the electron beam current for melting. The melting step time $t_{\mathrm{m}}$ in the thermal modelling is calculated as [20]:

$$
t_{\mathrm{m}}=\frac{d_{\mathrm{s}}}{v_{\mathrm{m}}}
$$

where $v_{\mathrm{m}}$ is the electron beam scanning speed during the material melting process. Equation (1) was computationally solved for $t_{\mathrm{m}}$ seconds for the active layer remelting process.

The computational melting cooling step time for each active layer is $10.45 \mathrm{~s}$, corresponding to the practical PBF-EB manufacturing process.

The above four processes (i.e., preheating step, preheating 'cooling' step, active layer melting step and melting cooling step) were repeated in the computational modelling until the end of the PBF-EB process, since which moment the volumetric heating source at the active layer of the simulation domain was set to be equal to zero (i.e., electron beam was turned off). Equation (1) was solved until the 2D part cooled to room temperature.

\subsubsection{Thermal Boundary Conditions}

Axisymmetric boundary condition was applied on the left boundary of the simulation domain (as shown in Figure 1). The solid base plate was isothermally kept at $773 \mathrm{~K}$ in the thermal modelling as well as in the practical PBF-EB trials.

The following heat losses were considered in the thermal modelling: heat conduction between the active layer (i.e., the newly added layer of powders) and the solidified material of the previous layer or the base plate, heat radiation at the top surface of the active layer to the chamber. The heat transfer between the powder bed and the side of the solidified part was dealt with in a way similar to heat convection, and the related details can be found in the authors' previous papers $[13,24,25]$. Due to the fact that the PBF-EB process is normally conducted in a vacuum environment, the heat convection at the top surface of the active layer was not considered in the modelling. The heat flux due to conduction can be formulated as [28]:

$$
q=-k \nabla T
$$

where $k$ is the temperature-dependent thermal conductivity of the material. The heat radiation at the top surface of the active layer was considered in the modelling before the next layer was added [13]:

$$
q_{\mathrm{rad}}=\varepsilon \sigma\left(T_{\mathrm{s}}^{4}-T_{\mathrm{r}}^{4}\right)
$$

where $q_{\mathrm{rad}}$ is the heat flux due to active layer radiation, $\varepsilon$ is the emissivity, $\sigma$ is the StefanBoltzmann constant, $T_{\mathrm{S}}$ is the surface temperature of the part and $T_{\mathrm{r}}$ is the build chamber temperature [29]. Here, the emissivity of the active layer surface $\varepsilon$ and the StephanBoltzmann's constant $\sigma$ were set as 0.35 [30] and $5.669 \times 10^{-8} \mathrm{~W} /\left(\mathrm{m}^{2} \cdot \mathrm{K}^{4}\right)$ [31], respectively.

The heat flux between the 2D part at its side surface and the surrounding powder bed $[13,24]$ can be formulated as:

$$
q_{\mathrm{conv}}=h\left(T_{\mathrm{s}}-T_{\mathrm{r}}\right)
$$

where $h$ is the heat transfer coefficient [30]. 


\subsubsection{Material Properties and Process Parameters}

For the PBF-EB thermal modelling, the material of both the part and the base plate was defined as Ti2448 to avoid thermal expansion mismatch [32]. The temperature dependent Ti2448 material properties that were employed in the computation were assumed to vary linearly with temperature between the values that are presented in Table 1 . The thermal conductivity and specific heat were detected by Flashline ${ }^{\mathrm{TM}}-5000$ Thermal Properties Analyzer according to GB/T 22588-2008. The PBF-EB process parameters were found from Arcam EBM User Mannual (Arcam AB, 2011, Mölndal, Sweden), as shown in Table 2.

Table 1. Ti2448 material properties.

\begin{tabular}{|c|c|c|c|}
\hline $\begin{array}{l}\text { Temperature } \\
\text { (K) }\end{array}$ & $\begin{array}{c}\text { Thermal Expansion } \\
\left(10^{-5} / \mathrm{K}\right)\end{array}$ & $\begin{array}{c}\text { Thermal Conductivity } \\
\left(\mathrm{W} / \mathrm{m}^{2} / \mathrm{K}\right)\end{array}$ & $\begin{array}{l}\text { Specific Heat } \\
(\mathrm{J} / \mathrm{kg} / \mathrm{K})\end{array}$ \\
\hline 333 & $0.87[33]$ & & \\
\hline 370 & & 8.35 & 478 \\
\hline 873 & & 15.8 & 445 \\
\hline 983 & $1.06[33]$ & & \\
\hline 1273 & & 19 & 470 \\
\hline 1928 & 1.35 [33] & & \\
\hline
\end{tabular}

Table 2. EBM process parameters.

\begin{tabular}{|c|c|c|c|}
\hline Symbol & Modelling Parameters & Unit & Value \\
\hline$U$ & Acceleration voltage & V & 60000 \\
\hline$I_{\mathrm{p}}$ & Current for preheating & $\mathrm{mA}$ & 14.6 \\
\hline$I_{\mathrm{m}}$ & Current for melting & $\mathrm{mA}$ & 8.5 \\
\hline$v_{\mathrm{m}}$ & Scanning speed for melting & $\mathrm{mm} / \mathrm{s}$ & 1704.3 \\
\hline$v_{\mathrm{p}}$ & Preheating scanning speed & $\mathrm{mm} / \mathrm{s}$ & 10000 \\
\hline$T_{\mathrm{p}}$ & Substrate preheat temperature & $\mathrm{K}$ & 773 \\
\hline$A$ & Heat source absorption coefficient & & $0.9[34]$ \\
\hline$d_{\mathrm{s}}$ & Heat source spot diameter for melting & $\mu \mathrm{m}$ & 200 \\
\hline$d_{\mathrm{m}}$ & Melt pool depth & $\mu \mathrm{m}$ & 150 \\
\hline \multirow[t]{2}{*}{$H$} & Hatch spacing & $\mu \mathrm{m}$ & 200 \\
\hline & Powder layer thickness & $\mu \mathrm{m}$ & 70 \\
\hline
\end{tabular}

\subsection{Experimental Methods}

\subsubsection{PBF-EB Printing Process}

Arcam A1 PBF-EB system was used to fabricate dense samples in this work with a $0.5 \mathrm{~mm}$ accuracy. The pre-alloyed powder (particle diameter ranges from 45 to $106 \mu \mathrm{m}$ ) used in PBF-EB process was produced by using argon atomization of a Ti2448 ingot. The chemical composition of the powder was (wt.\%) Nb-24.43, Zr-3.93, Sn-8.22, O-0.22 and Ti-bal. The CAD model of samples with a size of $\varphi 20 \times 20 \mathrm{~mm}$ was designed using Magics 17.0 (Materialise, Leuven, Belgium) software, and then the model was sliced and imported into PBF-EB equipment for parameters setting. The printing started after the vacuum in the build chamber and electron gun became under $5.0 \times 10^{-4} \mathrm{mbar}$ and $5.0 \times 10^{-6}$ mbar, respectively. The electron beam preheated the base plate with a dimension of $170 \times 170 \times 10 \mathrm{~mm}$ to $773 \mathrm{~K}$ for $20 \mathrm{~min}$, and then the equipment started to spread the powders for printing with a layer thickness of $70 \mu \mathrm{m}$. The electron beam moved by tracing out the designed geometry to melt the powders in the active layer of the powder bed and then the base plate got lowered by one layer thickness. These processes were repeated until the completion of the part. It was noted that the printing time of each layer was influenced by the melting area, and the printing procedure ended after $8 \mathrm{~h}$. When the base plate cooled to room temperature, the non-melted powder could be removed by compressed air to obtain the as-fabricated sample (Figure 2a). 
(a)

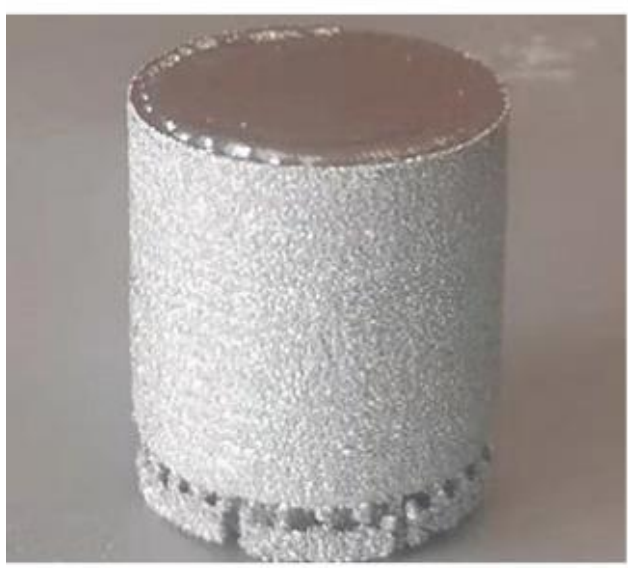

(b)

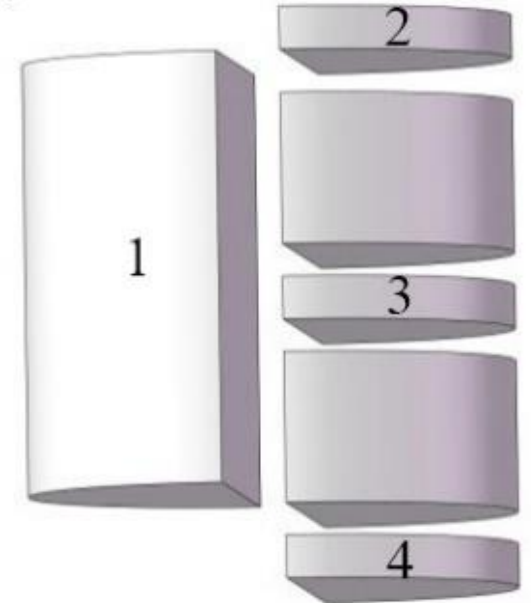

Figure 2. (a) Ti2448 sample manufactured by PBF-EB. (b) Sketch illustrating how the sample was sectioned for metallographic analysis. (Position-2, 3 and 4 is $18 \mathrm{~mm}, 10 \mathrm{~mm}$ and $2 \mathrm{~mm}$ from the base plate, respectively).

\subsubsection{Material Characterization Methods}

The samples were sectioned by using wire electric discharge machining (EDM) as shown in Figure $2 b$. The metallographic specimens were made at positions $1-4$, respectively, so as to characterise the material microstructure on the cross-sections of the sample and separately on a centre plane of the sample. The microstructural features of the prepared samples were analysed by using ZEISS-AXIO optical microscope (OM), MIRA3 TESCAN scanning electron microscope (SEM) and Talos transmission electron microscope (TEM). Metallographic samples for OM and SEM observations were etched in a reagent ( $2 \mathrm{vol} \%$ $\mathrm{HF}, 6 \mathrm{vol} \% \mathrm{HNO}_{3}$ and $92 \mathrm{vol} \% \mathrm{H}_{2} \mathrm{O}$ ) for $15 \mathrm{~s}$ until the crystal morphology could be seen clearly. Backscattered electron imaging (BSE) was used to examine mechanically polished samples without corrosion. The TEM samples were processed by twin-jet electropolishing (Tenupol-5), and the electrolyte was made of $6 \% \mathrm{HClO}_{4}, 59 \% \mathrm{CH}_{3} \mathrm{OH}$ and $35 \%$ $\mathrm{CH}_{3}\left(\mathrm{CH}_{2}\right)_{3} \mathrm{OH}$ in volume percent. The grain size in different locations of the sample was measured by electron back scatter diffraction (EBSD) with a step size of $6 \mu \mathrm{m}$, and the size of the detection area was $2.1 \times 2.3 \mathrm{~mm}$. The indexing rate of all the EBSD samples was higher than 95\%. The EBSD sample was electropolished in the electrolyte mentioned above. The data of grain size was exported from Channel 5 software with the grain boundary definition of $10^{\circ}$. To characterise the phases of material at positions $2-4$ of the as-fabricated sample, $\mathrm{X}$-ray diffraction (XRD, D8 DISCOVER with $\mathrm{Cu} \mathrm{K} \alpha$ radiation) measurement was conducted with a scanning angle range of $20^{\circ}-90^{\circ}$.

\subsection{Computation of Phase Equilibrium}

The equilibrium phase diagram of Ti2448 was calculated with the PANDAT 2020 (CompuTherm LLC, Middleton, MA, USA) package in association with the Ti- $\mathrm{Nb}-\mathrm{Zr}$ Sn-O thermal and mobility database covering the temperature range of $273 \mathrm{~K}-1273 \mathrm{~K}$. The two basic phases of Ti2448, i.e., $\alpha$ and $\beta$, were considered in the computation of phase equilibrium.

\section{Results}

\subsection{Thermal Modelling Results}

\subsubsection{Temperature Profile along the Height of the Manufactured Part}

In the thermal modelling, the part was virtually sliced into 286 layers and each layer was deposited on top of the previous layer step by step. The thermal modelling was implemented for $11 \mathrm{~h} 46.28 \mathrm{~min}$ of the PBF-EB process, including $3 \mathrm{~h} 3.28 \mathrm{~min}$ of the additive manufacturing process and the post-manufacturing cooling process of $8 \mathrm{~h}$ 
$43 \mathrm{~min}$. Temperature histories of the five vertical sampling points (VP1, VP2, VP3, VP4 and VP5, shown in Figure 1) are illustrated in Figure 3. In this figure, zone (a) illustrates the temperature of the active layer in question at the end of the corresponding melting process (step 3 of the computational modelling process). The maximum temperature was above $3200 \mathrm{~K}$, corresponding to the first peak of temperature for each curve (e.g., the curve corresponding to VP3). The deposition, preheating, melting and cooling processes of the subsequent layers of material caused periodic oscillation of temperature at the vertical sampling point in question. The influence of subsequent processes on the temperature history of the current layer (or vertical sampling point) in question can be found in zone (b).

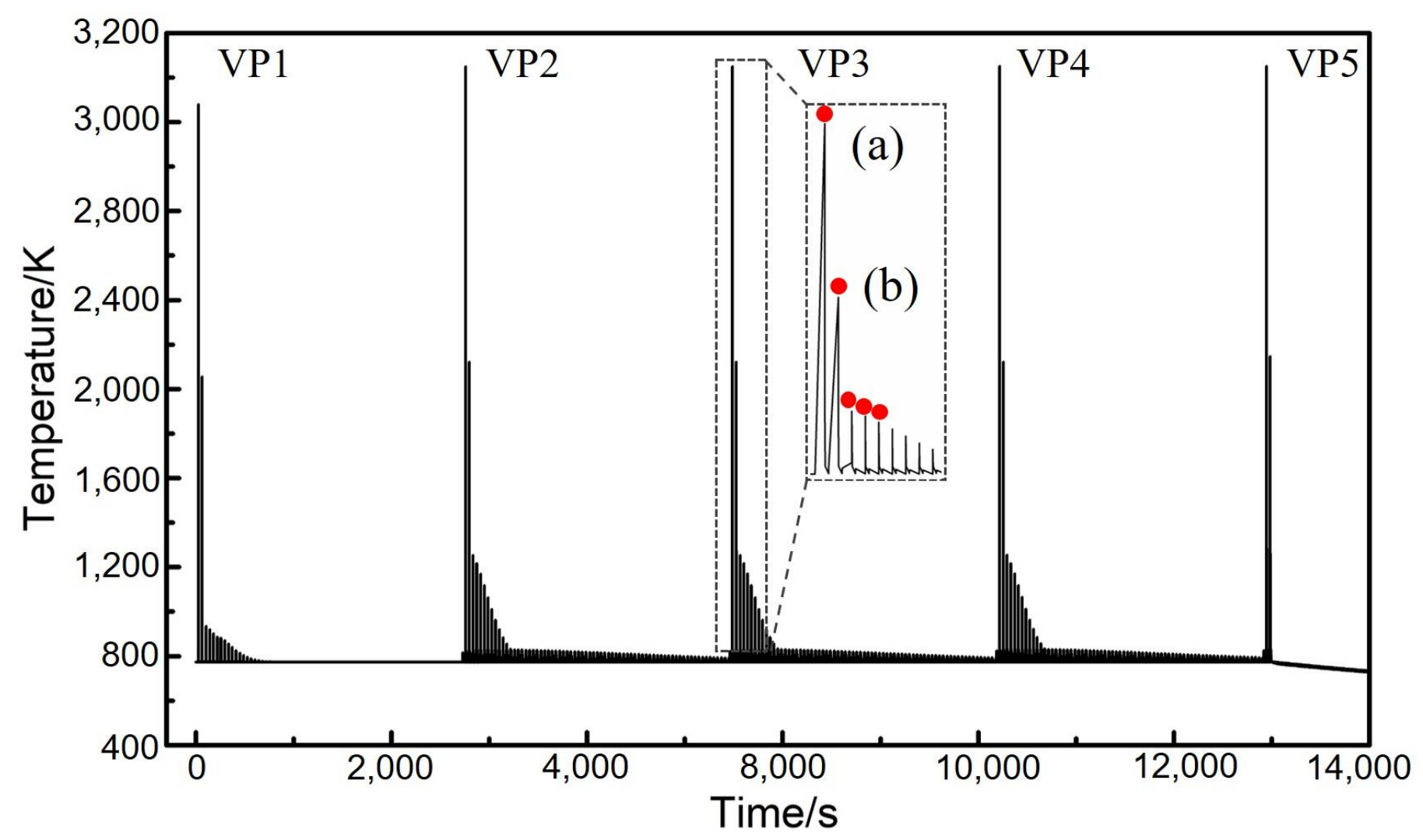

Figure 3. Evolution of temperature at the five vertical sampling points (VP1, VP2, VP3, VP4 and VP5) with time. (Zone (a) illustrates the thermal history of the active layer during melting and cooling, and zone (b) illustrates the influence of the subsequent processes on the temperature history of the current layer).

Figure 3 indicates that the temperature at the five vertical sampling points changed with time as the part was built layer upon layer. In order to enhance the visibility of the figure, the results are only illustrated up to $12,000 \mathrm{~s}$ of the PBF-EB process. With the deposition of sequential layers, the maximum temperatures at VP1 was always the lowest compared with the maximum temperature at the other four vertical sampling points, while the five vertical sampling points share similar temperature history (Figure 3). Overall, temperature increases from the bottom towards the top of the manufactured part during the PBF-EB process. The first deposition layer has the lowest temperature, because of the significant heat conduction to the base plate. With the sequential deposition of material, during the layer-by-layer PBF-EB process, the thermal influence of the base plate on the newly laid layer of material gradually becomes less significant. Therefore, the temperature temporal evolution near the mid height of the part (e.g., VP2, VP3 and VP4) becomes relatively unaffected by the height of the vertical sampling points, and the corresponding three curves in Figure 3 are similar. This agrees with the findings in other PBF-EB process studies [34]. The temperature temporal evolution at VP5 is relatively different from that of other four vertical sampling points, as no further layers were added after $3 \mathrm{~h} 3.28 \mathrm{~min}$. The 
temperature at VP5 only oscillates for two cycles, and it quickly starts to monotonically decrease. After finishing the manufacturing of the part, the part was eventually cooled to room temperature during the post-printing cooling process.

In order to characterise the temperature variation of the part in the vertical direction during the PBF-EB process, the peak temperature of each thermal cycle was chosen to make the peak temperature variation curve of VP1-VP5 sampling points with time, as shown by the red dot in Figure 3a,b. It can be seen that there exists very rapid periodic oscillation of material in temperature during the AM process due to the layer-by-layer approach. In order to make the temporal evolution of temperature more visible, the peak temperature of each thermal cycle and how it evolves with time at respective vertical sampling points is shown in Figure 4a. It can be seen that the peak temperature increases gradually from VP1 to VP4. Moreover, the temperature difference (TD) is defined, which is the peak temperature at the sampling points of VP2, VP3, VP4 and VP5 (Figure 1) of the part minus the peak temperature at VP1. The evolution of TD with time at respective vertical sampling points is shown in Figure $4 \mathrm{~b}$. It can be seen that the TD values are all positive, which further confirms that the temperature of material near the base plate is the lowest in the overall part. The temporal evolutions of the TD at VP2, VP3 and VP4 are very similar to one another. At VP2, for example, during the deposition, preheating, melting and cooling of the active layer, the TD decreased from approximately $2675 \mathrm{~K}$ to $\sim 1 \mathrm{~K}$. Such a process is not monotonic but significantly oscillates up and down because the deposition, preheating, melting and cooling of the PBF-EB is repetitive. Overall, it can be seen that the value of TD at VP4 is higher than VP3, and that at VP3 is higher than VP2. This further confirms an increasing temperature profile of the part along its height.

(a)

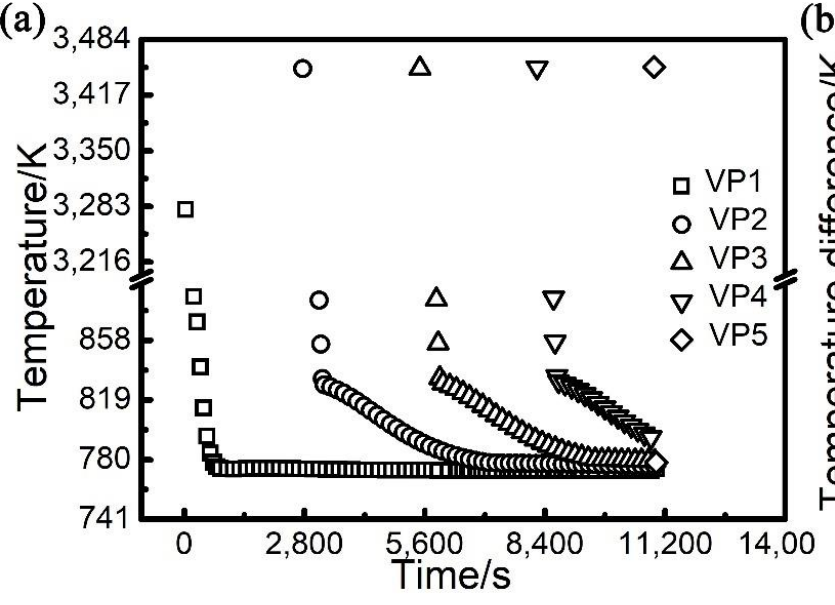

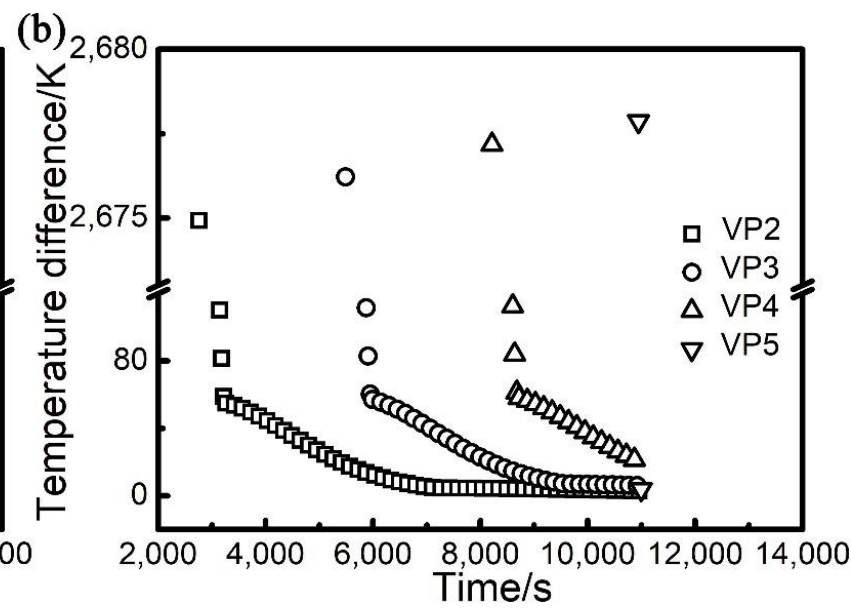

Figure 4. Evolution of peak temperature (a) and temperature difference (b) with time at different points along the building direction of the studied sample shown in Figure 1.

The cooling rate at the five vertical sampling points (Figure 1) was calculated based on the temperature history that is shown in Figure 3. Figure 5a illustrates the maximum cooling rate at respective vertical sampling points up to the end of the melting step (as shown in Figure $3 a$ ). Figure $5 b$ illustrates the maximum cooling rate at the vertical sampling points, which results from the influence of the subsequent layers (as shown in Figure 3b). It can be seen that the highest level of cooling rate is in the order of magnitude of $10^{5} \mathrm{~K} / \mathrm{s}$. It is close to the practically measured results of $10^{5} \sim 10^{6} \mathrm{~K} / \mathrm{s}$ in other work $[35,36]$. Figure $5 \mathrm{a}$ indicates that the peak cooling rate occurred immediately after the completion of the melting step (Figure 3a) of the active layer. During the process of the subsequent layers (Figure 3b), the cooling rate at the vertical sampling points in question significantly decreased. It can be seen, as shown in Figure 5, that the cooling rate at the sampling point VP1 is the highest. It is higher than the cooling rate at VP2, VP3, VP4 and VP5 by approximately $3 \times 10^{4} \mathrm{~K} / \mathrm{s}$. This is due to the fact that the isothermal base plate took the role of a powerful heat sink 
that very effectively extracted heat by conduction from the part at its bottom during the PBF-EB process. A similar decrease in the cooling rate along the building direction of alloy 718 is found in other work [37].

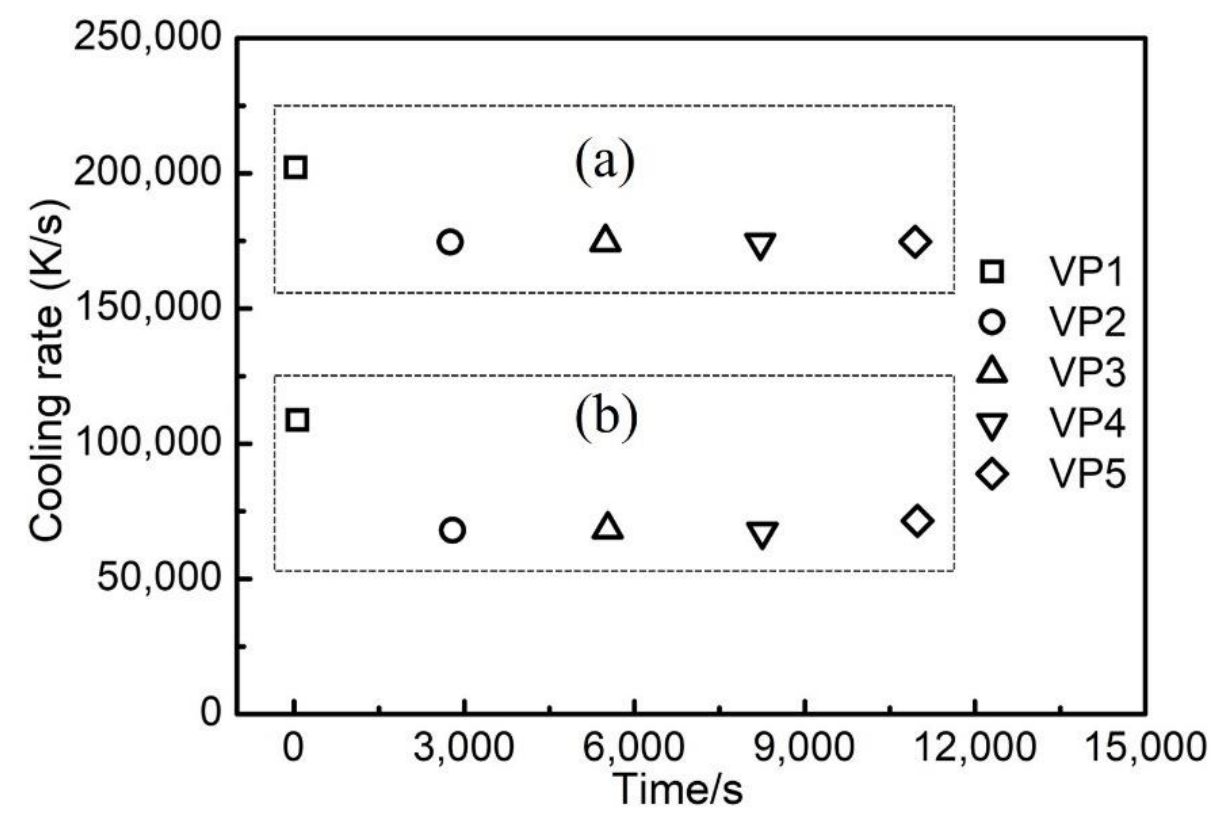

Figure 5. Maximum cooling rate at the five vertical sampling points: (a) at the end of the melting process of the layer in question, (b) resulting from the thermal processes of subsequent layers.

\subsubsection{Temperature Profile in the Radial Direction of the Manufactured Part}

The peak temperature of the material at radial sampling points (RP1 to RP5) of the manufactured part reflects the material temperature distribution along the radial direction. Their evolution with time along the VP3 layer is shown in Figure 6a. It can be seen that the peak temperature decreases from RP1 to RP5 on the VP3 layer. The TD in the radial direction of the manufactured part is defined to be the temperature at the four radial sampling points RP2, RP3, RP4, RP5 minus the temperature at the sampling point RP1 (as shown in Figure 1), at the mid-height of the manufactured part. Its evolution with time is shown in Figure 6b. It can be seen that the value of TD is negative, which means that the temperatures at RP2, RP3, RP4 and RP5 was lower than that at RP1 during the PBF-EB process. TD has the highest absolute value at RP5. Overall, the temperature near the surface of the part is lower than that near the centreline of the part, and there is a decreasing profile of temperature along the radius of the part. This phenomenon was caused by the heat loss of the part to the surrounding powder bed at the side surface of the part $[13,22]$. The absolute value of TD in the radial direction decreases with time at all the sampling points (RP2 to RP5), which is due to the heat conduction process in the part tends to make the temperature profile uniform, as increasingly more materials are deposited above the mid-height of the part. 

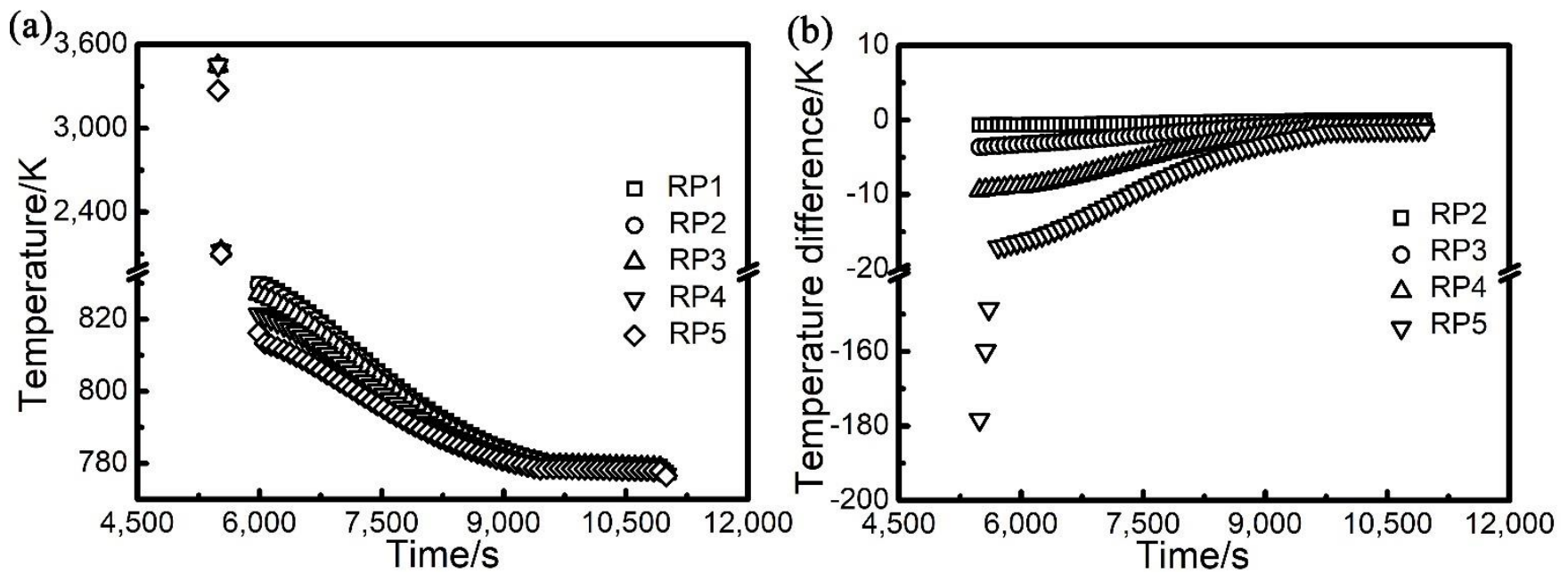

Figure 6. Evolution of peak temperature (a) and temperature difference (b) with time at different radial sampling points along the radial direction of the studied sample shown in Figure 1.

The maximum cooling rate at the five radial sampling points RP1, RP2, RP3, RP4 and RP5 of the VP3 layer is shown in Figure 7. During the processes of material deposition, preheating and melting of the layer at the mid height of the part, the highest cooling rate was in the order of magnitude of $10^{5} \mathrm{~K} / \mathrm{s}$. It can be seen in Figure 7, the surface of the part (i.e., at RP5) has the highest level of cooling rate, which is higher than the cooling rate at $\mathrm{RP} 1, \mathrm{RP} 2, \mathrm{RP} 3$ and RP4 by approximately $1 \times 10^{4} \mathrm{~K} / \mathrm{s}$. As the subsequent layers were deposited on the part above its mid height, the cooling rate at the sampling points RP1, RP2, RP3 and RP4 significantly decreased to the order of magnitude of $7 \times 10^{4} \mathrm{~K} / \mathrm{s}$, while the cooling rate at RP5 decreased to the order of magnitude of $9 \times 10^{4} \mathrm{~K} / \mathrm{s}$ (Figure $7 \mathrm{~b}$ ).

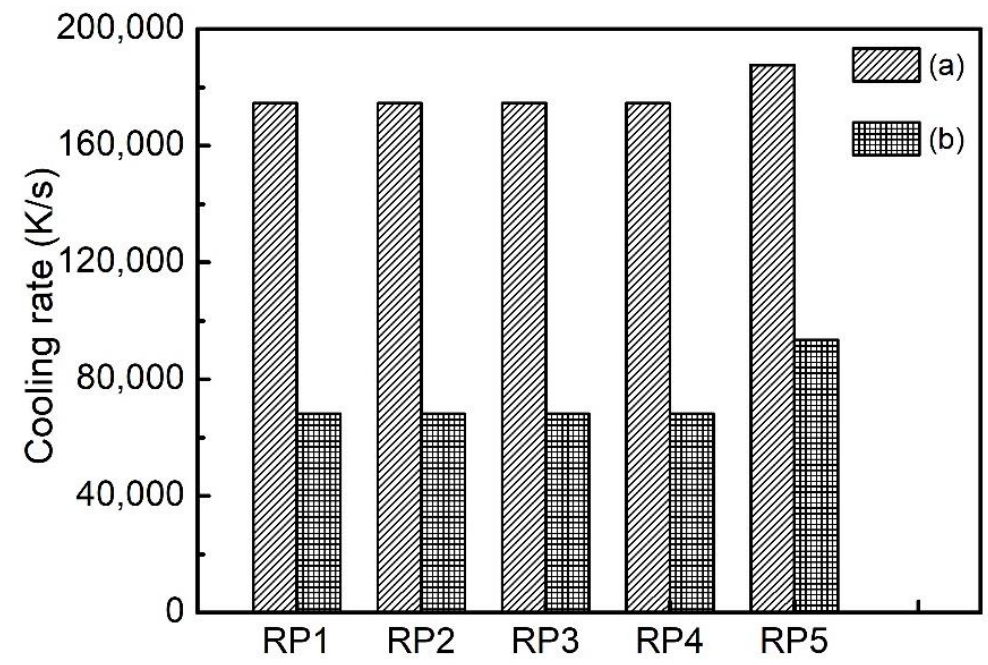

Figure 7. Maximum cooling rate at the five radial sampling points: (a) at the end of the melting process of the layer in question, (b) resulting from the thermal processes of subsequent layers.

\subsubsection{Thermal Process during the Natural Cooling Process Post Manufacturing}

In the thermal modelling results that were analysed in Sections 3.1.1 and 3.1.2, the data analysis was focused on the manufacturing process, i.e., the step No. 1, 2, 3, 4 of the physical PBF-EB process. After the manufacturing process was completed, the manufactured part was left in the build chamber to cool for a period of time before it could be taken out. Figure 8 illustrates the thermal modelling results of the temperature evolution of the part at the five vertical sampling positions with time during the natural cooling process post manufacturing. It can be seen that at vertical sampling point VP1 in this figure, the material 
temperature continuously decreased from $774 \mathrm{~K}$ to $426 \mathrm{~K}$ between $3 \mathrm{~h} 3.28 \mathrm{~min}$ and $11 \mathrm{~h}$ $46.28 \mathrm{~min}$. The temperature evolutions at the five different vertical sampling points are very close to one another, and the maximum difference in temperature is $7.3 \mathrm{~K}$. The temperature at the top surface of the part is lower than that at the bottom of the part. In the radial direction of the sample, the temperature profile turns out to be relatively uniform. The maximum difference in temperature between the five radial sampling positions is $0.87 \mathrm{~K}$.

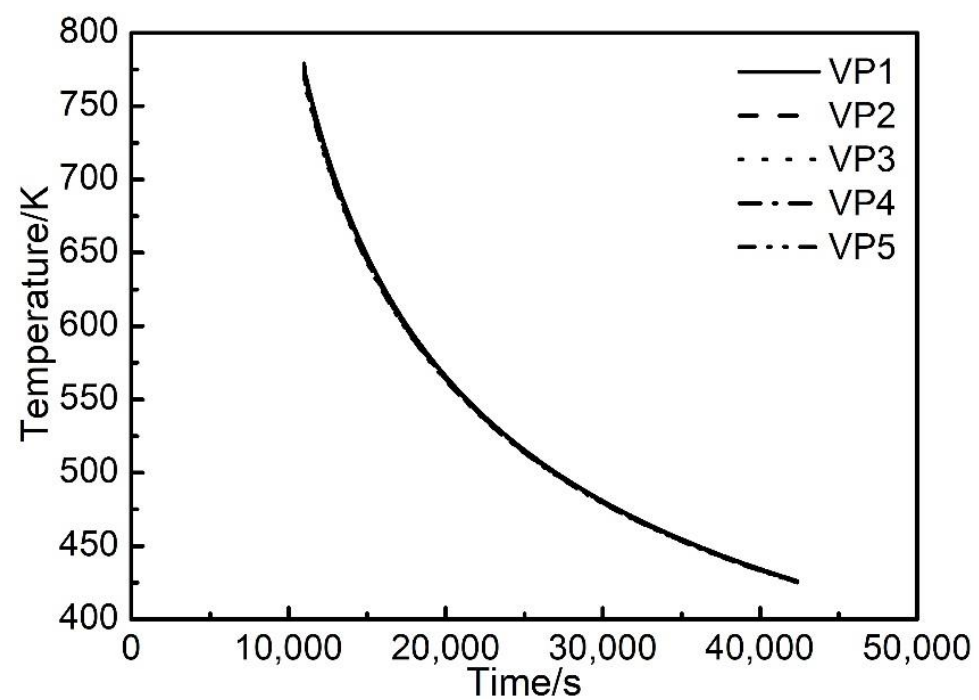

Figure 8. Evolution of temperature of the part at the five vertical sampling points with time during natural cooling process post manufacturing.

\subsection{Material Characterization Results}

Figure 9a,b show the microstructure characteristics of the PBF-EB produced Ti2448 sample. The PBF-EB sample displays a microstructure with coarse columnar grains and fine lath phases. There are a small amount of fine lath phases distributed on the grain boundaries and inside the grains according to the SEM and BSE images of the crosssection of the sample. Comparing the Bright-Field image (Figure 9c) with the High-Angle Annular Dark Field image (Figure 9d), it is found that the composition of precipitates is different from that of the matrix. It is verified by TEM observation that the fine lath phase is an orthorhombic structure precipitated from $\beta$ columnar grains (Figure 10). The precipitates at the grain boundaries and in the grains have the same structure. Comparing the microstructure of material at the cross-section and vertical section (Figures 11 and 12), it can be seen that coarse columnar $\beta$ grains tend to form parallel to the building direction, and a layer of equiaxed grains is distributed near the baseplate. Such a microstructure is the inherent feature of the additive manufacturing process and is consistent with the results elsewhere [38]. Observing the distribution trend of the precipitates at the positions 2-4 (Figure 2b), it can be seen that the content of fine lath phase decreases from the bottom to the top along the building direction of the sample, and only very limited precipitates can be seen on the top of the part (Figure 11A-2). In addition, it can be seen that more fine lath phase exists near the side surface of the sample than that around the centre line of the sample at the same height (Figure 11B-2 and A-2). It can be seen in Table 3 that the $\beta$ grain size increases slightly along the building direction of the sample. Meanwhile, the $\beta$ grain size near the centre line of the sample is larger than that near the side surface of the sample. 

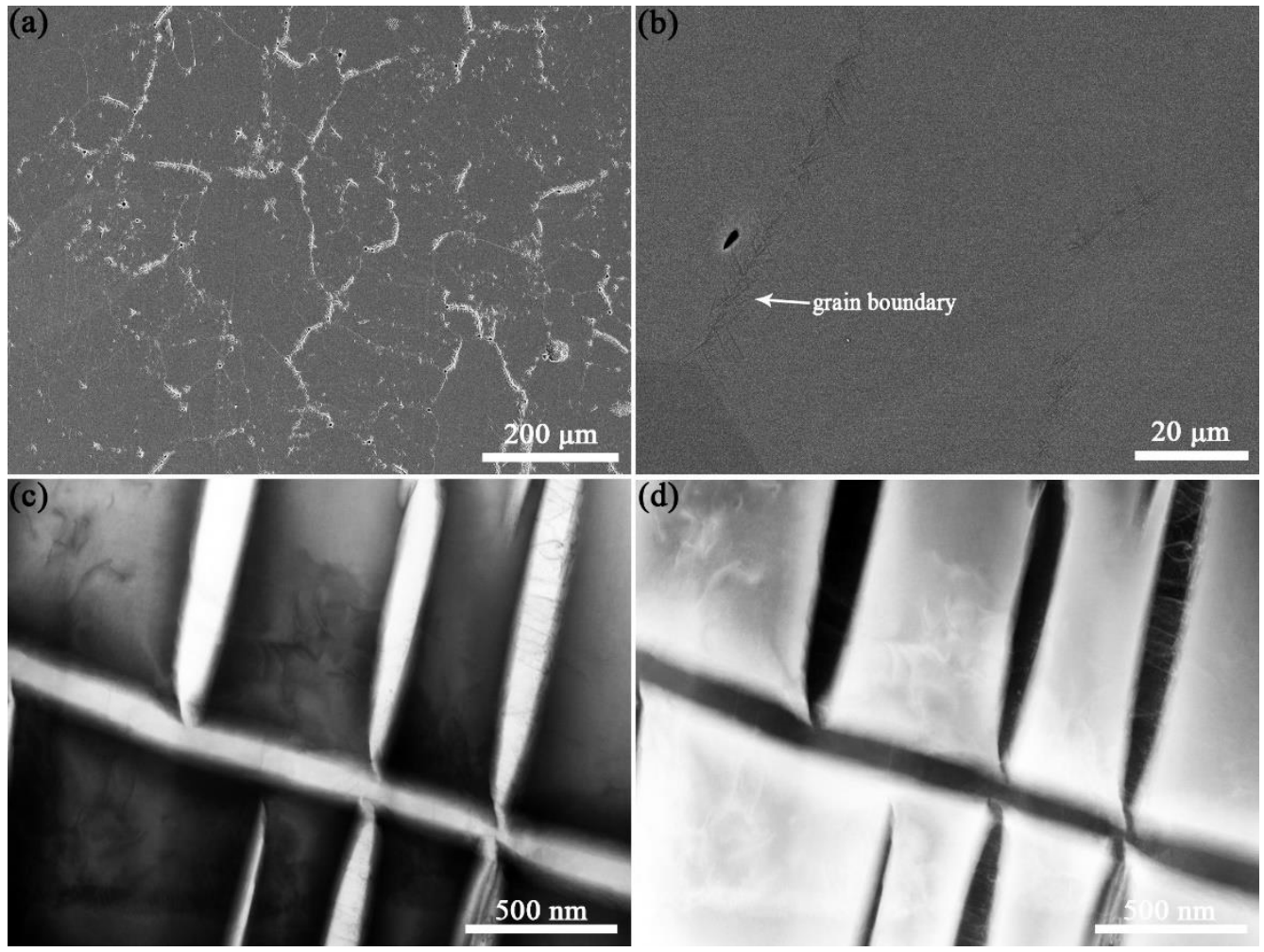

Figure 9. SEM image (a), BSE image (b), Bright-Field STEM image (c) and High-Angle Annular Dark Field image (d) of the cross-section of the sample. The BSE image (b) and High-Angle Annular Dark Field image (d) indicates that the composition of precipitates is different from that of matrix.

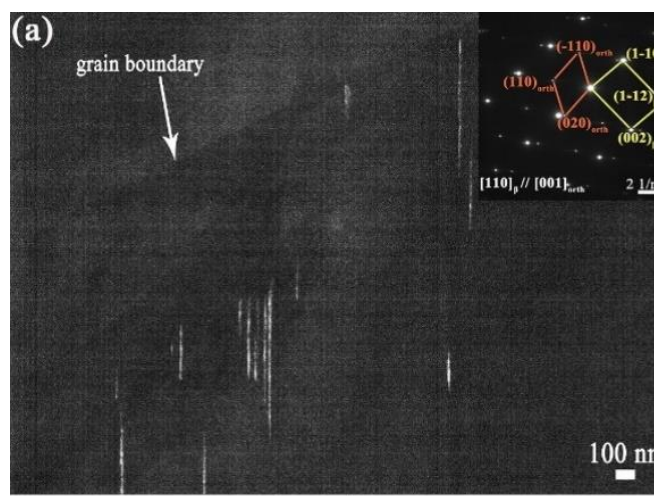

(b)
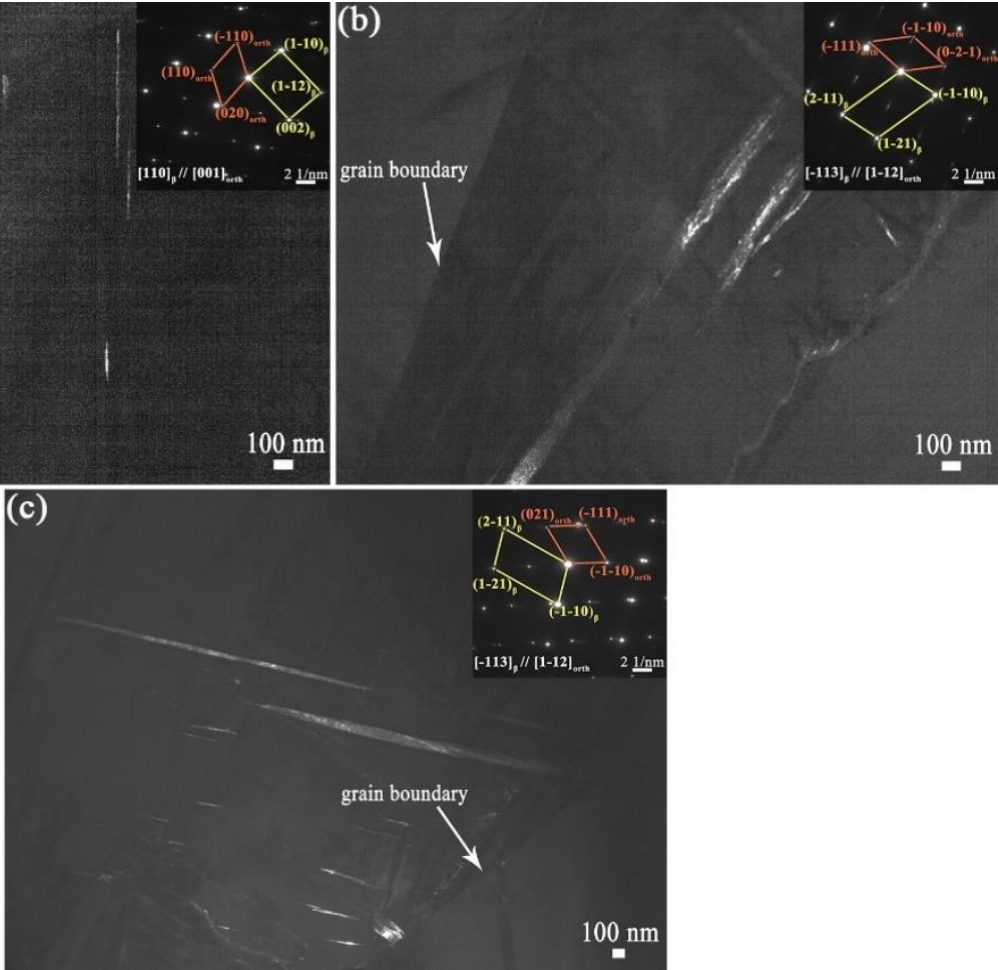

Figure 10. Dark-Field TEM image and Selected-Area Diffraction image of Position 2 (a), Position 3 (b), Position 4 (c) shown in Figure $2 b$. 


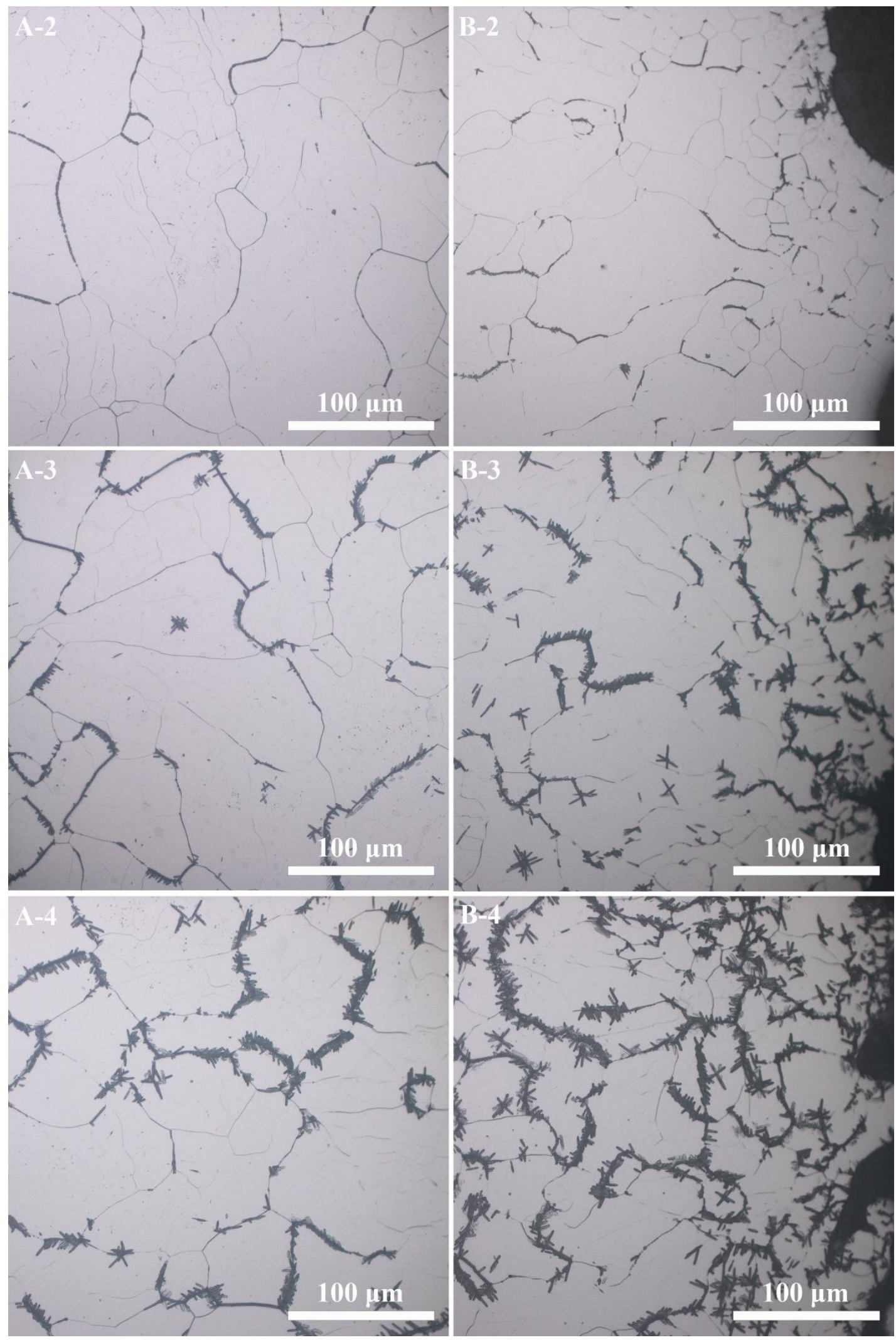

Figure 11. Optical image of the cross-section in different segments of the sample. (The pictures with the letter (" $\left.\mathrm{A}^{\prime \prime}\right)$ represents the central area of the cross-section, and the pictures with the letter ("B") represents the cross-section of sample near its side surface. Number $2-4$ on the pictures represents segment $2-4$ as illustrated in Figure $2 b$ ). 

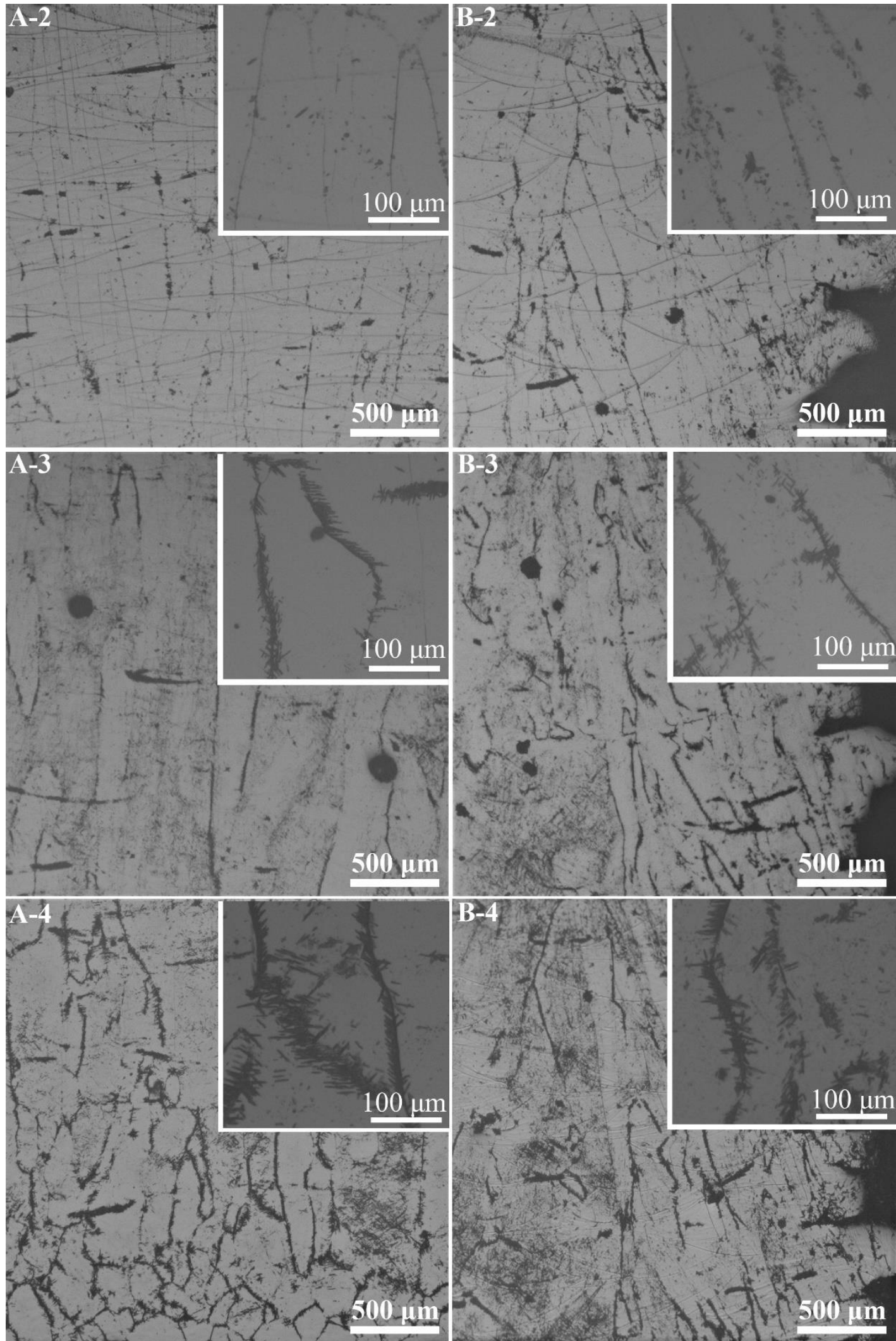

Figure 12. Optical image of vertical section in different segments of sample. (The pictures with the letter (" $\left.\mathbf{A}^{\prime \prime}\right)$ represents the central area of the vertical section, and the pictures with the letter ("B") represents the vertical section of the sample near its surface. Numbers $2-4$ on the pictures represent the top, middle, bottom segments on the vertical section, respectively, as shown in Figure 2b). 
Table 3. $\beta$ Grain size $(\mu \mathrm{m})$ at different segments on the sample.

\begin{tabular}{ccc}
\hline $\begin{array}{c}\text { Position } \begin{array}{c}\text { Along the Height of } \\
\text { Sample }\end{array} \\
\text { Around Sample Centre Line }\end{array}$ & Around Sample Side Surface \\
\hline Middle & $111.0 \pm 59.2$ & $90.8 \pm 67.1$ \\
Bottom & $65.3 \pm 30.9$ & $57.2 \pm 29.1$ \\
\hline
\end{tabular}

(The lognormal distribution function was used to fit the data, and the average value and standard deviation were taken as the grain size data at different positions of the sample, as shown in Figure 11.)

By analysing the XRD diffraction patterns of the sample at positions $2-4$ as illustrated in Figure $2 \mathrm{~b}$ and excluding a few heteropeaks caused by experimental artefacts, it can be concluded that there are $\alpha^{\prime \prime}$ phase and $\beta$ phase in the Ti2448 alloy manufactured by PBF-EB (Figure 13a). Given that X-ray diffraction analysis shows that the studied sample has a similar texture at different positions along height direction, the ratio of peak height of the $\alpha^{\prime \prime}$ phases with respect to the $\beta$ phase is used to describe the variation of volume fractions of the $\alpha^{\prime \prime}$ phases along the height of the sample. It can be seen that the height ratios of (021)orth to (110) $\beta$ peaks decreases with the increase of sample height (Figure 13b). This phenomenon indicates that the content of the $\alpha^{\prime \prime}$ phase decreases with the increase of sample height [39], which is consistent with the distribution law of microstructure pictures.
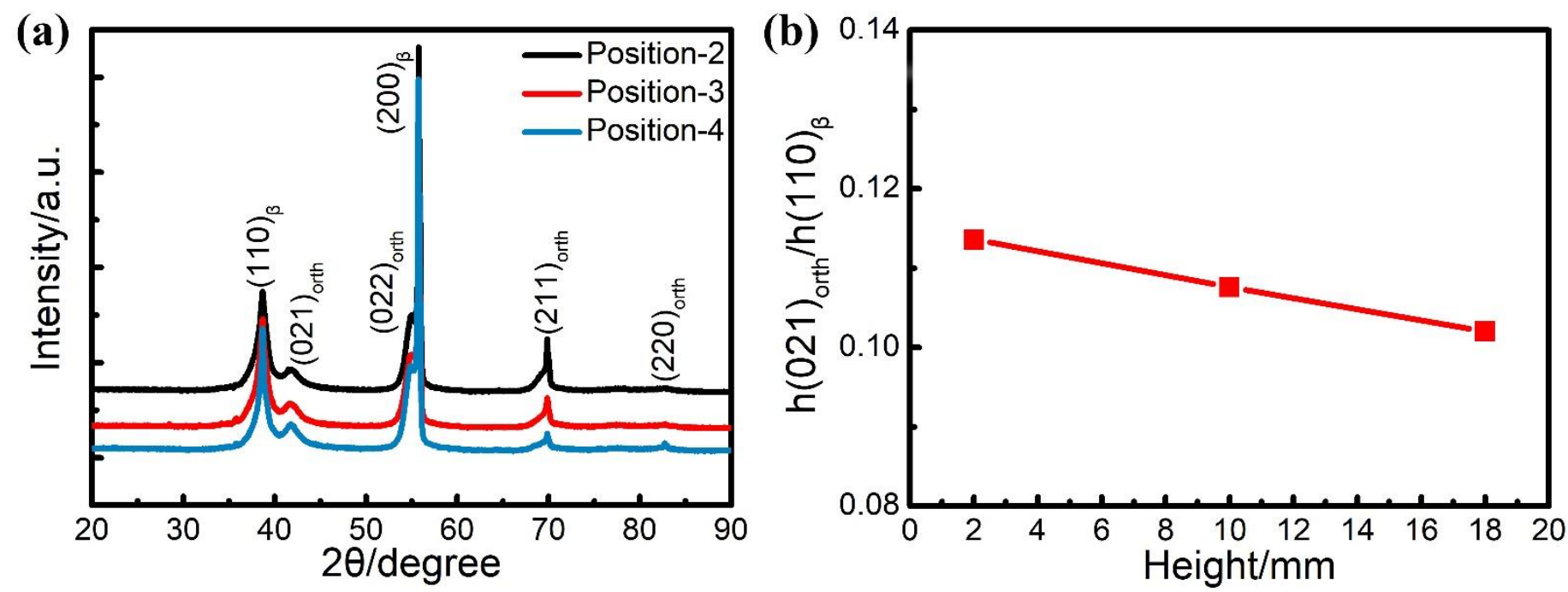

Figure 13. XRD analysis results of PBF-EB Ti2448 alloy at different heights. (a) XRD diffraction patterns of Ti2448 sample at positions $2-4$ shown in Figure $2 b$. (b) The change of height ratios of diffraction peak (021) orth to (110) $\beta$ along the height direction.

\section{Discussion}

\subsection{Variation of the $\alpha$ "Phase}

Metastable $\beta$-titanium alloys generally exhibit a single $\beta$ phase at room temperature. In the isothermal aging process, the transitional phase (the $\alpha^{\prime \prime}$ phase or $\omega$ phase) will precipitate from the supersaturated $\beta$ phase, and it will gradually evolve into equilibrium $\alpha$ phase with the extension of aging time [40,41]. For the isothermal $\omega$ phase, it forms by solute diffusion i.e., it rejects $\beta$-stabilising elements into the matrix during aging and the collapse of two of every three $(222)_{\beta}$ planes in the $[111]_{\beta}$ direction into a single plane [42]. The $\omega$ precipitates were found to be strongly deficient in $\mathrm{Nb}$ and weakly deficient in $\mathrm{Zr}$ for the Ti-24Nb-[0-8]Zr (at.\%) alloys [43]. The $\omega$ phase can provide the dominant nucleation position for $\alpha$ phase, which is conducive to the precipitation of $\alpha$ phase [44]. The solute redistribution occurs at the very beginning of the $\beta$ decomposition process, resulting in the composition fluctuation on the matrix. The $\beta_{\text {stabilizer }}$ lean region is unstable and easy to transform into an orthorhombic structure by shear and shuffle mechanisms [45]. During 
aging, the $\alpha^{\prime \prime}$ phase was observed to evolve toward a hexagonal $\alpha$ structure [46]. For the equilibrium $\alpha$ phase, the phase transition path can be described as the shear of the \{112\} [47] plane along the [111] direction accompanied by the shuffling of the cross atomic layers and the uniform contraction along the specific crystal direction [48]. The formation of $\alpha$ phase is a diffusion- displacement type phase transition, which is similar to the formation of $\omega$ phase and $\alpha^{\prime \prime}$ phase. The $\alpha$ phase can precipitate directly from $\beta$ matrix or be transformed from a transition phase [49]. The morphology and distribution of $\alpha$ phase are related to the heat treatment or processing conditions $[50,51]$.

For hot-rolled Ti2448 alloy, the main transformation path during aging is $\beta$ phase (bcc) $\rightarrow \alpha$ " phase (orth) $\rightarrow \alpha$ phase (hcp). There are equiaxed $\mathrm{Nb}$-rich and $\mathrm{Nb}$-lean regions with an average size of $2-3 \mathrm{~nm}$ in hot-rolled Ti2448 alloy [52,53]. In the process of phase transformation, the $\mathrm{Nb}$-lean region first transforms into $\alpha^{\prime \prime}$ phase whose structure is close to the $\beta$ matrix (bcc), then the structure of $\alpha^{\prime \prime}$ phase continuously evolves towards hcp via orthorhombic structure when the solute diffusion and lattice distortion proceed simultaneously. Finally, the $\beta \rightarrow \alpha$ phase transformation is completed [54]. It is reported that the $\alpha^{\prime \prime}$ phase precipitates from $\beta$ matrix of Ti2448 alloy during aging at 648-848 K [55].

The calculated thermal history of the studied sample (Figures 3,4 and 6 ) shows that the temperature of the sample is kept in the range of $648 \mathrm{~K}$ to $848 \mathrm{~K}$ during the most time of the PBF-EB process, which is also the temperature range of $\alpha$ " phase precipitation in Ti2448 alloy [39]. This may facilitate the $\alpha^{\prime \prime}$ phase precipitation in the studied samples, as confirmed by the XRD (Figure 13) results shown in Section 3. It is interesting that the content of $\alpha^{\prime \prime}$ phase decreases along the building direction and increases along the radial direction (Figure 11). The reasons for the variation of $\alpha$ " phase content can be summarized as follows: Firstly, aging time can significantly affect the content of precipitates. According to Figure 3 , the temperatures of the sampling points VP1-VP4 are approximately stable around the level of $773 \mathrm{~K}$ after several cycles of drastic temperature fluctuations. This stage is similar to the aging process, which is conducive to the precipitation of $\alpha^{\prime \prime}$ phase. The longer the aging time at the precipitation temperature range of $\alpha^{\prime \prime}$ phase, the more $\alpha^{\prime \prime}$ phase will precipitate. In the PBF-EB process, the aging time of the sampling points in the temperature range of 773-848 K decreases from VP1 to VP4 in the building direction (Figure 3), which is the main reason for the content of $\alpha^{\prime \prime}$ phase decreases along the building direction. Secondly, aging temperature is also an important factor affecting the content of precipitates. The calculated equilibrium phase diagram of Ti-24Nb-4Zr-7.85Sn-0.22O (wt.\%) alloy is shown in Figure 14. It can be seen from this figure that the content of $\alpha$ phase decreases with the increase of temperature before the transus point, while that of $\beta$ phase shows an opposite trend. Given that the $\alpha^{\prime \prime}$ phase is the intermediate phase of $\beta \rightarrow \alpha$ transformation, the change of $\alpha^{\prime \prime}$ phase content with temperature is similar to that of $\alpha$ phase. Therefore, the positive temperature gradient of VP1-VP5 (Figures 4 and 15) and negative temperature gradient of RP1-5 (Figures 6 and 15) caused the decreasing profile of $\alpha^{\prime \prime}$ phase in the building direction and increasing profile of $\alpha^{\prime \prime}$ phase in the radial direction, respectively. 


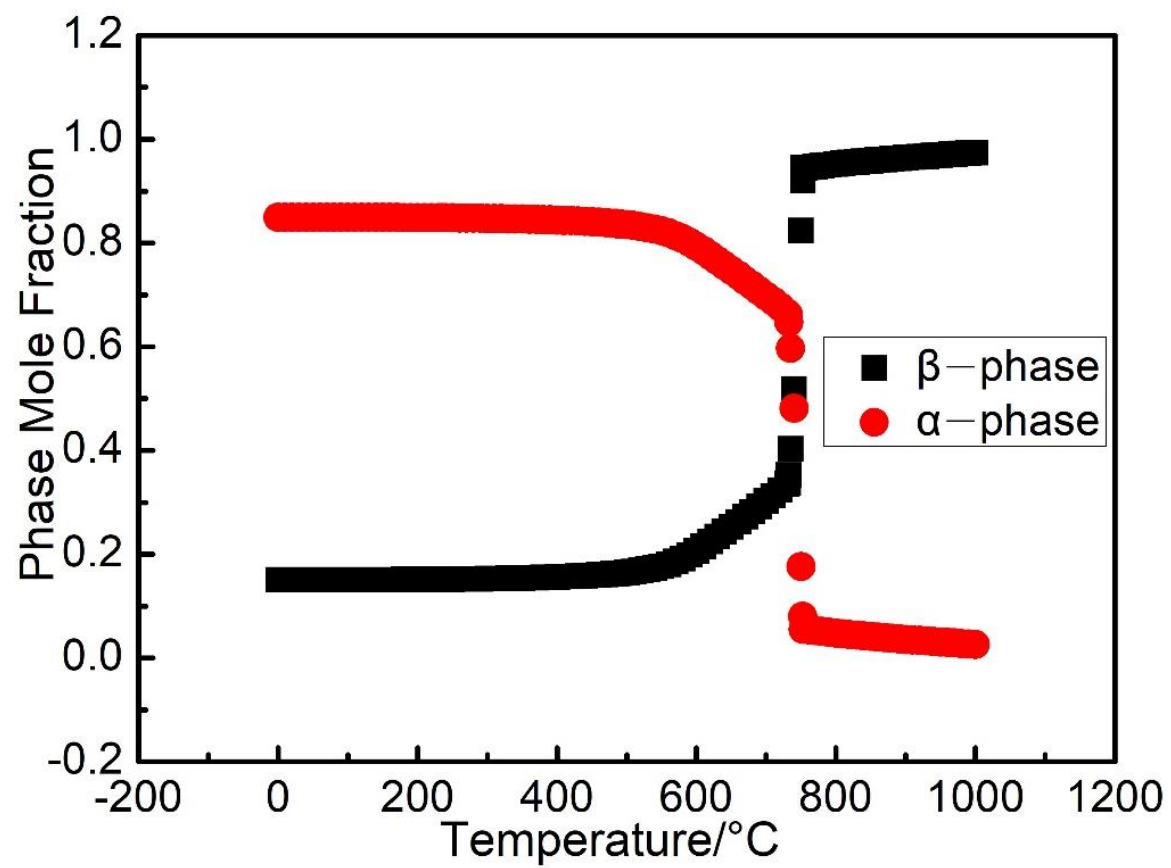

Figure 14. The calculated equilibrium phase diagram of Ti-24Nb-4Zr-7.85Sn-0.22O (wt.\%) alloy.

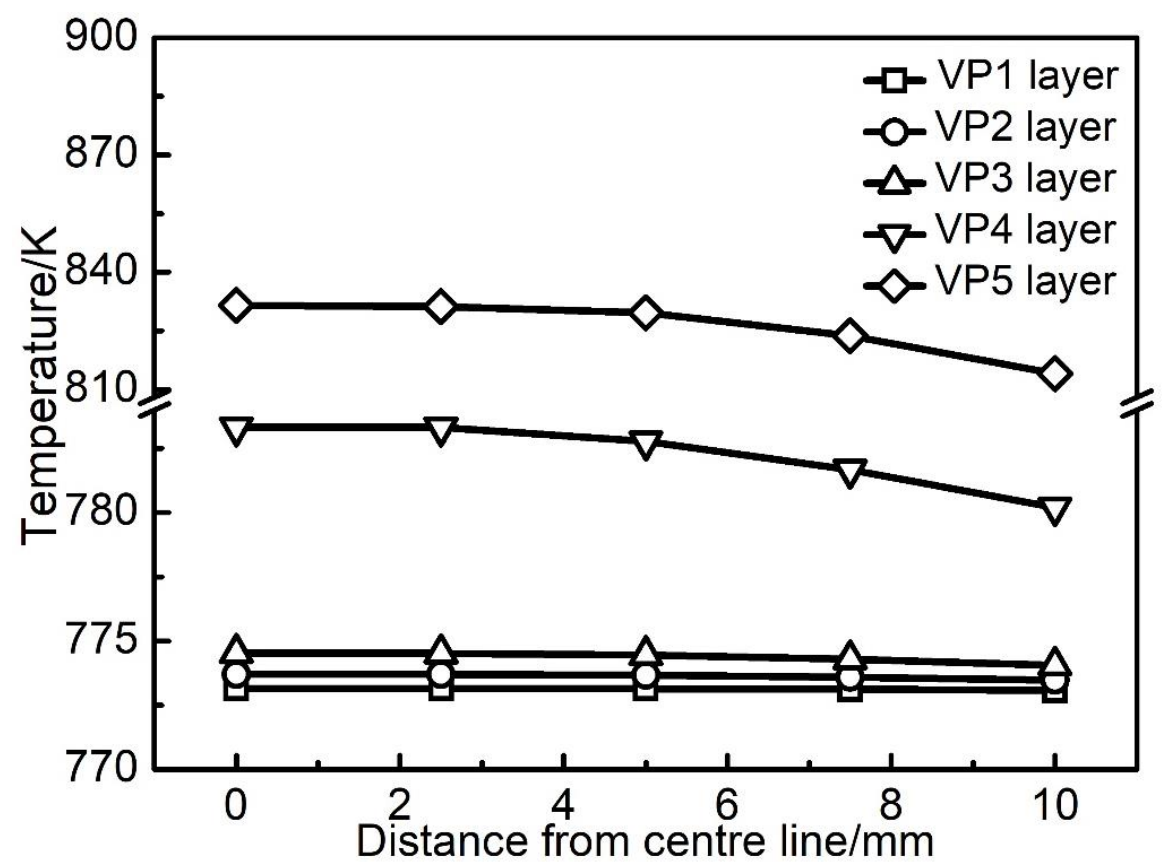

Figure 15. Temperature profile along the radial direction of VP1-VP5 layers of the sample shown in Figure 1 at 10,986.9 s (when the melting process of the sample ends).

\subsection{Variation of $\beta$ Grain Size}

It is reported that the equiaxed grain layer near the substrate is formed by heterogeneous nucleation due to co-melting and alloying of deposited powders material close to the base plate [56]. PBF-EB process can result in a high cooling rate and great thermal gradient on the solidification front. The thermal gradient is conducive to grain growth along the preferred crystal direction, and it also promotes the formation of epitaxy between layers, resulting in unidirectional columnar grain growth in additively manufactured parts [38]. In addition, the composition of liquid and solid are similar during PBF-EB, as a result, the wettability of the liquid phase at the surface of the solid phase of the same 
alloy during PBF-EB is excellent and the wetting angle approaches $0^{\circ}$ [57]. This means no nucleation barrier upon remelting and solidifying of the previous layer is present, so the columnar $\beta$ grains can elongate through multiple layers. The reasons for the variation of grain size are summarized as follows: Firstly, the temperature is a main factor affecting grain growth. It is known that the aging temperature has more effect than the aging time on grain size. Figure 15 shows the temperature profiles along the building direction and the radial direction at $10986.9 \mathrm{~s}$, when the last layer of the sample has been melted and before the completion of the manufacturing process. The temperature at the top of the sample is $58 \mathrm{~K}$ higher than that at the bottom, which is conducive to the rapid growth of grains, making the grain size at the top of the sample slightly larger than that at the bottom (Table 3). Due to the decreasing temperature profile along the radial direction (Figure 6), the $\beta$ grains near the sample surface are smaller than those near the sample centre line. Secondly, the cooling rate is another mechanism affecting $\beta$ grain size. A high cooling rate is not beneficial to grain growth [58]. As shown in Figure 7, the cooling rate at the side surface of the sample is significantly higher than that at the centre of the sample on the same height. The grains near the centre of the sample are easier to grow than the grains at the side surface, so the grain size has a decreasing profile in the radial direction of the sample. Besides, the partially melted powder at the contact interface between the part and the powder bed provides a large number of heterogeneous nucleation points, which is helpful to reduce the grain size $[4,56]$. This paper only discusses the influence of thermal history on the variation trend of precipitates content and grain size.

\section{Conclusions}

In this study, the thermal process of PBF-EB was computationally predicted by using the layer-by-layer modelling method. The microstructure of PBF-EB-Ti2448 alloy was characterized by OM, SEM, TEM and XRD, which mainly consists of $\alpha$ " phase and small amount of $\beta$ phase. The computational modelling results of temperature histories, temperature differences and cooling rates along the height and radius of a cylinder part have revealed the driving factors behind the experimentally observed profiles of $\alpha^{\prime \prime}$ phase fraction and $\beta$ grain size in multiple directions. Overall, due to heat conduction between the consolidated part and the surrounding powder bed as well as heat radiation, material temperature is higher at the top of the part compared with that the bottom of the part. The temperature at the side surface of the cylindrical part is lower than that near the centreline of the part. The highest cooling rate is at the bottom of the part and the side surface of the part. Such thermal processes of PBF-EB and the corresponding temperature profile of part during AM result in different aging times and different temperatures at different sections of a manufactured sample. They caused a gradient along sample height and a gradient along the sample radius in $\alpha$ phase content and in grain size. This work could be further developed into an integrated through-process thermal history based microstructural evolution model, similar to recent computational PBF-LB [59,60] and weld [61,62] simulation tools. Such tools can be used by experimentalists and in industry to optimise the design of PBF-EB process parameters to achieve optimal material microstructures in order to benefit in-service mechanical performance.

Author Contributions: Q.W. and W.Z. contributed equally to this work; M.T. and S.L. obtained funding for the project; R.Y., N.M.H. and Y.H. reviewed and edited the paper; W.Z. and H.W. performed the simulation; W.H. manufactured the samples; Q.W. performed the experiments and analyzed the results. All authors wrote the article together. All authors have read and agreed to the published version of the manuscript.

Funding: Chinese MoST (2017YFC1104903), Key Research Program of Frontier Sciences, CAS (QYZDJ-SSW-JSC031-02), National Natural Science Foundation of China (51771209, 51631007, 51871220, 81902191), CAS Interdisciplinary Innovation Team Project (JCTD-2020-10) of China, State Key Laboratory of Light Alloy Casting Technology for High-end Equipment (LACT-007), Shenyang Talents program (RC200230), the Irish Research Council (GOIPG/2018/2488), Science Foundation Ireland (16/RC/3872). 
Institutional Review Board Statement: Not applicable.

Informed Consent Statement: Not applicable.

Data Availability Statement: Data sharing is not applicable for this article.

Acknowledgments: This work was supported partially by Chinese MoST (2017YFC1104903), Key Research Program of Frontier Sciences, CAS (QYZDJ-SSW-JSC031-02), National Natural Science Foundation of China $(51771209,51631007,51871220,81902191)$, CAS Interdisciplinary Innovation Team Project (JCTD-2020-10) of China, State Key Laboratory of Light Alloy Casting Technology for High-end Equipment (LACT-007) and Shenyang Talents program (RC200230). The authors from NUI Galway grateful acknowledge the funding by the Irish Research Council (GOIPG/2018/2488) under the Government of Ireland Postgraduate Programme, the Hardiman Research Scholarship, and the College of Engineering and Informatics Scholarship of NUI Galway. The authors wish to acknowledge the Irish Centre for High-End Computing (ICHEC) for the provision of computational facilities and support. This publication has emanated from research supported in part by a grant from Science Foundation Ireland under Grant number 16/RC/3872. For the purpose of Open Access, the author has applied a CC BY public copyright licence to any Author Accepted Manuscript version arising from this submission.

Conflicts of Interest: The authors declare no conflict of interest.

\section{Nomenclature}

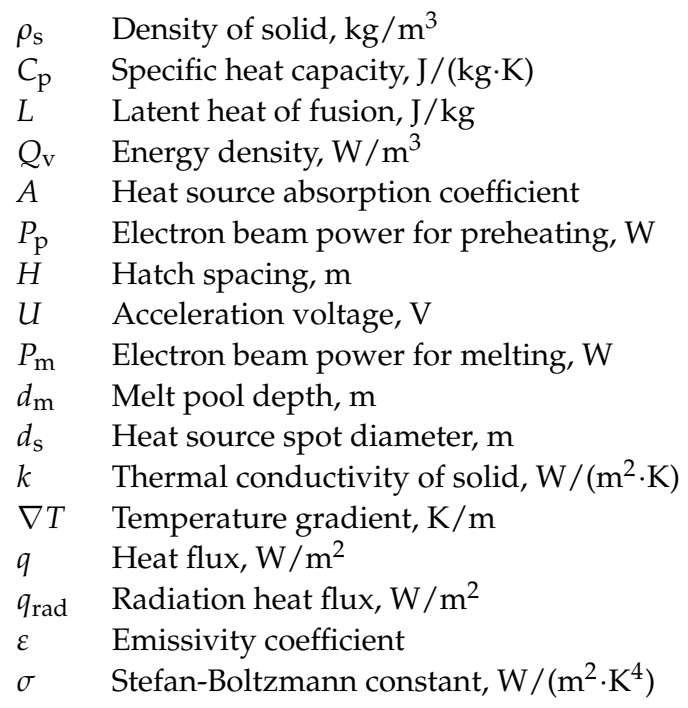

\section{References}

1. ISO. DIN EN ISO/ASTM 52900 Additive Manufacturing_General Principles_Terminology; ISO: Geneve, Switzerland, 2018.

2. Yan, W.; Lin, F.; Liu, W. An effective Finite Element heat transfer model for Electron Beam Melting process. In Proceedings of the Advances in Materials and Processing Technologies Conference, Madrid, Spain, 14-17 December 2015.

3. Murr, L.E.; Li, S. Electron-beam additive manufacturing of high-temperature metals. MRS Bull. 2016, 41, 752-757. [CrossRef]

4. Antonysamy, A.A.; Meyer, J.; Prangnell, P.B. Effect of build geometry on the $\beta$-grain structure and texture in additive manufacture of Ti6Al4V by selective electron beam melting. Mater. Charact. 2013, 84, 153-168. [CrossRef]

5. Sames, W.J.; Unocic, K.A.; Dehoff, R.R.; Lolla, T.; Babu, S.S. Thermal effects on microstructural heterogeneity of Inconel 718 materials fabricated by electron beam melting. J. Mater. Res. 2014, 29, 1920-1930. [CrossRef]

6. Rannar, L.E.; Koptyug, A.; Olsen, J.; Saeidi, K.; Shen, Z.J. Hierarchical structures of stainless steel 316L manufactured by Electron Beam Melting. Addit. Manuf. 2017, 7, 106-112. [CrossRef]

7. Cheng, B.; Price, S.; Lydon, J.; Cooper, K.; Chou, K. On Process Temperature in Powder-Bed Electron Beam Additive Manufacturing: Model Development and Validation. J. Manuf. Sci. Eng. 2014, 136, 6. [CrossRef]

8. Shen, N.G.; Chou, K. Thermal Modeling of Electron Beam Additive Manufacturing Process: Powder Sintering Effects. In Proceedings of the Asme International Manufacturing Science \& Engineering Conference Collocated with the North American Manufacturing Research Conference \& in Participation with the International Conference on Tribology Materials \& Processing, Xiamen, China, 27-29 March 2012; pp. 287-295. 
9. Prabhakar, P.; Sames, W.J.; Dehoff, R.; Babu, S.S. Computational modeling of residual stress formation during the electron beam melting process for Inconel 718. Addit. Manuf. 2015, 7, 83-91. [CrossRef]

10. Galati, M.; Iuliano, L. A literature review of powder-based electron beam melting focusing on numerical simulations. Addit. Manuf. 2018, 19, 1-20. [CrossRef]

11. Li, C.; Liu, F.; Guo, Y.B.; Li, Z.Y. A Temperature-Thread Multiscale Modeling Approach for Efficient Prediction of Part Distortion by Selective Laser Melting. In Proceedings of the 26th Annual International Solid Freeform Fabrication Symposium, Austin, TX, USA, 10-12 August 2015.

12. Williams, R.J.; Davies, C.M.; Hooper, P.A. A pragmatic part scale model for residual stress and distortion prediction in powder bed fusion. Addit. Manuf. 2018, 22, 416-425. [CrossRef]

13. Zhang, W.; Tong, M.; Harrison, N.M. Resolution, energy and time dependency on layer scaling in finite element modelling of laser beam powder bed fusion additive manufacturing. Addit. Manuf. 2019, 28, 610-620. [CrossRef]

14. Hao, Y.L.; Li, S.J.; Zheng, C.Y.; Hu, Q.M.; Yang, R. Super-elastic titanium alloy with unstable plastic deformation. App. Phys. Lett. 2005, 87, 091906. [CrossRef]

15. Hao, Y.L.; Li, S.J.; Sun, S.Y.; Zheng, C.Y.; Yang, R. Elastic deformation behaviour of Ti-24Nb-4Zr-7.9Sn for biomedical applications. Acta Biomater. 2007, 3, 277-286. [CrossRef]

16. Hao, Y.L.; Li, S.J.; Yang, R. Biomedical titanium alloys and their additive manufacturing. Rare Metals 2016, 35, 661-671. [CrossRef]

17. Hernandez, J. Microstructures and Hardness Properties for $\beta$-Phase Ti-24Nb-4Zr-7.9Sn Alloy Fabricated by Electron Beam Melting. J. Mater. Sci. Technol. 2013, 11, 1011-1017. [CrossRef]

18. Yang, C.L.; Zhang, Z.J.; Li, S.J.; Sercombe, T.B.; Hou, W.T.; Zhang, P.; Zhu, Y.K.; Hao, Y.L.; Zhang, Z.F. Simultaneous improvement in strength and plasticity of Ti-24Nb-4Zr-8Sn manufactured by selective laser melting. Mater. Des. 2018, 157, 52-59. [CrossRef]

19. Liu, Y.J.; Li, S.J.; Wang, H.L.; Hou, W.T.; Hao, Y.L. Microstructure, defects and mechanical behavior of beta-type titanium porous structures manufactured by electron beam melting and selective laser melting. Acta Mater. 2016, 113, 56-67. [CrossRef]

20. Zhang, Y.C.; Guillemot, G.; Bernacki, M.; Bellet, M. Macroscopic thermal finite element modeling of additive metal manufacturing by selective laser melting process. Comput. Methods Appl. Mech. Eng. 2018, 331, 514-535. [CrossRef]

21. Barrett, R.A.; Barrett, R.A.; Etienne, T.; Duddy, C.; Harrison, N.M. Residual Stress Prediction in a Powder Bed Fusion Manufactured Ti6Al4V Hip Stem. Am. Inst. Phys. Conf. Ser. 2017. [CrossRef]

22. Zhang, W.Y. Process Modelling and Experimental Validation of Residual Stress in Metal Additive Manufacturing. NUI Galway 2022.

23. Yan, W.T.; Ge, W.J.; Smith, J.; Lin, S.; Kafka, O.L.; Lin, F.; Liu, W.K. Multi-scale modeling of electron beam melting of functionally graded materials. Acta Mater. 2016, 115, 403-412. [CrossRef]

24. Zhang, W.; Tong, M.; Noel, M.; Harrison, N.M. Data on a computationally efficient approximation of part-powder conduction as surface free convection in powder bed fusion process modelling. Data Brief 2019, 27, 104559. [CrossRef] [PubMed]

25. Zhang, W.Y.; Tong, M.M.; Harrison, N.M. Scanning strategies effect on temperature, residual stress and deformation by multi-laser beam powder bed fusion manufacturing. Addit. Manuf. 2020, 36, 101507. [CrossRef]

26. Michaleris, P. Modeling metal deposition in heat transfer analyses of additive manufacturing processes. Finite Elem. Anal. Des. 2014, 86, 51-60. [CrossRef]

27. Bayat, M.; Mohanty, S.; Hattel, J.H. A systematic investigation of the effects of process parameters on heat and fluid flow and metallurgical conditions during laser-based powder bed fusion of Ti6Al4V alloy. Int. J. Heat Mass Transf. 2019, 139, 213-230. [CrossRef]

28. Li, C.; Fu, C.H.; Guo, Y.B.; Fang, F.Z. A multiscale modeling approach for fast prediction of part distortion in selective laser melting. J. Mater. Process. Technol. 2016, 229, 703-712. [CrossRef]

29. Zhao, X.; Zhao, X.R.; Iyer, A.; Promoppatum, P.; Yao, S.C. Numerical modeling of the thermal behavior and residual stress in the direct metal laser sintering process of titanium alloy products. Addit. Manuf. 2017, 14, 126-136. [CrossRef]

30. Masoomi, M.; Thompson, S.M.; Shamsaei, N. Laser powder bed fusion of Ti-6Al-4V parts: Thermal modeling and mechanical implications. Int. J. Mach. Tools Manuf. 2017, 118-119, 73-90. [CrossRef]

31. Khairallah, S.A.; Anderson, A.T.; Rubenchik, A.; King, W.E. Laser powder-bed fusion additive manufacturing: Physics of complex melt flow and formation mechanisms of pores, spatter, and denudation zones. Acta Mater. 2016, 108, 36-45. [CrossRef]

32. Protasov, C.E.; Khmyrov, R.S.; Grigoriev, S.N.; Gusarov, A.V. Selective laser melting of fused silica: Interdependent heat transfer and powder consolidation. Int. J. Heat Mass Transf. 2017, 104, 665-674. [CrossRef]

33. Lu, X.F.; Lin, X.; Chiumenti, M.; Cervera, M.; Li, J.J.; Ma, L.; Wei, L.; Hu, Y.L.; Huang, W.D. Finite element analysis and experimental validation of the thermomechanical behavior in laser solid forming of Ti-6Al-4V. Addit. Manuf. 2018, 21, 30-40. [CrossRef]

34. Ding, X.; Yuichiro, K.; Wei, D.X.; Akihiko, C. Effect of process parameters on melt pool geometry and microstructure development for electron beam melting of IN718: A systematic single bead analysis study. Addit. Manuf. 2019, 26, 215-226. [CrossRef]

35. Criales, L.E.; Yiğit, M.A.; Brandon, L.; Shawn, M.; Alkan, D.; Tuğrul, O. Laser powder bed fusion of nickel alloy 625: Experimental investigations of effects of process parameters on melt pool size and shape with spatter analysis. Int. J. Mach. Tools Manuf. 2017, 121, 22-36. [CrossRef]

36. Wang, Z.H.; Lin, X.; Kang, N.; Hu, Y.L.; Chen, J.; Huang, W.D. Strength-ductility synergy of selective laser melted Al-Mg-Sc-Zr alloy with a heterogeneous grain structure. Addit. Manuf. 2020, 34, 101260. [CrossRef] 
37. Karimi, P.; Sadeghi, E.; Åkerfeldt, P.; Ålgårdh, J.; Andersson, J. Influence of successive thermal cycling on microstructure evolution of EBM-manufactured alloy 718 in track-by-track and layer-by-layer design. Mater. Des. 2018, 160, 427-441. [CrossRef]

38. Antonysamy, A.A. Microstructure, Texture and Mechanical Property Evolution during Additive Manufacturing of Ti6Al4V Alloy for Aerospace Applications. University of Manchester. 2012. Available online: http://www.manchester.ac.uk/escholar/uk-acman-scw:160535 (accessed on 9 May 2012).

39. Hao, Y.L.; Yang, R.; Niinomi, M.; Kuroda, D.; Zhou, Y.L.; Fukunaga, K.; Suzuki, A. Young's modulus and mechanical properties of Ti-29Nb-13Ta-4.6Zr in relation to $\alpha$ " martensite. Metall. Mater.Trans. A 2002, 33, 3137-3144. [CrossRef]

40. Ivasishin, O.M.; Markovsky, P.E.; Semiatin, S.L.; Ward, C.H. Aging response of coarse- and fine-grained $\beta$ titanium alloys. Mater. Eng. A 2005, 405, 296-305. [CrossRef]

41. Terlinde, G.; Fischer, G. Beta Titanium Alloys. Titan. Titan. Alloy. 2003, 37-57. [CrossRef]

42. Moffat, D.L.; Kattner, U.R. Stable and metastable Ti-Nb phase diagrams. Metall. Trans. 1988, 19, 2389-2397. [CrossRef]

43. Pang, E.L.; Pickering, E.J.; Baik, S.I.; Seidman, D.N.; Jones, N.G. The effect of zirconium on the omega phase in Ti-24Nb-[0-8]Zr (at.\%) alloys. Acta Mater. 2018, 153, 62-70. [CrossRef]

44. Wang, L.Q. Effect of Aging Treatment on Microstructure and Mechanical Properties of Ti27Nb2Ta3Zr $\beta$ Titanium Alloy for Implant Applications. J. Magn. Magn. Mater. 2004, 278, 1-8. [CrossRef]

45. Bönisch, M.; Stoica, M.; Calin, M. Routes to control diffusive pathways and thermal expansion in Ti-alloys. Sci. Rep. 2020, 10, 1-9. [CrossRef]

46. Aeby-Gautier, E.; Settefrati, A.; Bruneseaux, F.; Appolaire, B. Isothermal $\alpha$ " formation in $\beta$ metastable titanium alloys. J. Alloy. Compd. 2012, 577, S439-S443. [CrossRef]

47. Ahmadi, A.; Mirzaeifar, R.; Moghaddam, N.S.; Turabi, A.S.; Haluk, E.K.; Elahinia, M. Effect of manufacturing parameters on mechanical properties of 316L stainless steel parts fabricated by selective laser melting: A computational framework. Mater. Des. 2016, 112, 328-338. [CrossRef]

48. Burgers, W.G. On the process of transition of the cubic-body-centered modification into the hexagonal-close-packed modification of zirconium. Physica 1934, 1, 561-586. [CrossRef]

49. Rhodes, C.G.; Williams, J.C. The precipitation of $\alpha$-phase in metastable $\beta$-phase Ti alloys. Metall. Trans. A 1975. [CrossRef]

50. Williams, J.C. (Ed.) Titanium and Titanium Alloys Scientific and Technological Aspects Volume 3; Springer Science \& Business Media: Cham, Switzerland, 2013.

51. Banerjee, S.; Mukhopadhyay, P. Phase Transformations-Examples from Titanium and Zirconium Alloys Volume 12; Elsevier: Amsterdam, The Netherlands, 2007.

52. Wang, H.L.; Shah, S.A.A.; Hao, Y.L.; Prima, F.; Li, T.; Cairney, J.M.; Wang, Y.D.; Wang, Y.; Obbard, E.G.; Li, S.J.; et al. Stabilizing the body centered cubic crystal in titanium alloys by a nano-scale concentration modulation. J. Alloy. Compd. 2017, 700, 155-158. [CrossRef]

53. Wang, H.L.; Hao, Y.L.; He, S.Y.; Li, T.; Cairney, J.M.; Wang, Y.D.; Wang, Y.; Obbard, E.G.; Prima, F.; Du, K.; et al. Elastically confined martensitic transformation at the nano-scale in a multifunctional titanium alloy. Acta Mater. 2017, 135, 330-339. [CrossRef]

54. Hao, Y.L.; Gong, D.L.; Li, T.; Wang, H.L.; Cairney, J.M.; Wang, Y.D.; Obbard, E.G.; Sun, F.; Prima, F.; Li, S.J.; et al. Continuous and reversible atomic rearrangement in a multifunctional titanium alloy. Materialia 2018, 2, 1-8. [CrossRef]

55. Wang, H.L.; Hao, L.Y.; He, S.Y.; Du, K.; Li, T.; Obbard, E.G.; Hudspeth, J.; Wang, G.J.; Wang, Y.D.; Wang, Y.; et al. Tracing the coupled atomic shear and shuffle for a cubic to a hexagonal crystal transition. Scripta Mater. 2017, 133, 70-74. [CrossRef]

56. Al-Bermani, S.; Blackmore, M.L.; Zhang, W.; Todd, I. The Origin of Microstructural Diversity, Texture, and Mechanical Properties in Electron Beam Melted Ti6A14V. Metall. Mater. Trans. A 2010, 41, 3422-3434. [CrossRef]

57. Porter, D.; Easterling, K. Phase Transformations in Metals and Alloys Third Edition; CRC Press: Boca Raton, FL, USA, 1992.

58. Han, S.K.; Kobayashi, Y.; Tsukamoto, S.; Nagai, K. Effect of cooling rate on microstructure evolution of rapidly cooled highimpurity steels. Mater. Sci. Eng. A 2005, 403, 311-317. [CrossRef]

59. Yang, X.Y.; Barrett, R.A.; Tong, M.M.; Harrison, N.M.; Leen, S.B. Towards a process-structure model for Ti-6Al-4V during additive manufacturing. J. Manuf. Process. 2021, 61, 428-439. [CrossRef]

60. Yang, X.Y.; Barrett, R.A.; Tong, M.M.; Harrison, N.M.; Leen, S.B. Prediction of Microstructure Evolution for Additive Manufacturing of Ti-6Al-4V. Procedia Manuf. 2020, 47, 1178-1183. [CrossRef]

61. Ardghail, P.M.; Harrison, N.M.; Leen, S.B. A through-process, thermomechanical model for predicting welding-induced microstructure evolution and post-weld high-temperature fatigue response. Int. J. Fatigue 2018, 112, 216-232. [CrossRef]

62. Ardghail, P.M.; Harrison, N.M.; Leen, S.B. A process-structure-property model for welding of 9 Cr power plant components: The influence of welding process temperatures on in-service cyclic plasticity response. Int. J. Press. Vessel. Pip. 2019, 173, 26-44. [CrossRef] 